\title{
Location of functional groups in mycobacterial meromycolate chains; the recognition of new structural principles in mycolic acids
}

\author{
Motoko Watanabe, ${ }^{1}$ Yutaka Aoyagi, ${ }^{1}$ Hidemichi Mitome, ${ }^{1}$ \\ Tsuyoshi Fujita, ${ }^{2}$ Hideo Naoki, ${ }^{2}$ Malin Ridell ${ }^{3}$ and David E. Minnikin ${ }^{4}$
}

Author for correspondence: Motoko Watanabe. Tel: +81426 76 3040. Fax: +81 426763040. e-mail: motokoko@ps.toyaku.ac.jp

1 School of Pharmacy, Tokyo University of Pharmacy and Life Science, Horinouchi, Hachioji, Tokyo, 192-0392 Japan

2 Suntory Institute for Bioorganic Research, Wakayamadai, Shimamotocho, Mishimagun, Osaka, 618-8503 Japan

3 Department of Medical Microbiology, University of Gothenburg, Guldhedsgatan 10, S-41346 Gothenburg, Sweden

4 School of Biosciences, The University of Birmingham, Edgbaston, Birmingham B15 2TT, UK

\begin{abstract}
Mycobacterial $\alpha$-, methoxy- and keto-mycolic acid methyl esters were separated by argentation chromatography into mycolates with no double bond, with one trans double bond or with one cis double bond. Meromycolic acids were prepared from each methyl mycolate fraction by pyrolysis, followed by silver oxide oxidation, and analysed by high-energy collision-induced dissociation/fast atom bombardment MS to reveal the exact locations of the functional groups within the meromycolate chain. The locations of cis and trans double bonds, cis and trans cyclopropane rings, methoxy and keto groups, and methyl branches within the meromycolate chain were determined from their characteristic fragment ion profiles, and the structures of the meromycolic acids, including those with three functional groups extracted from Mycobacterium tuberculosis H37Ra, Mycobacterium bovis BCG and Mycobacterium microti, were established. Meromycolic acids with one cis double bond were structurally closely related to those with one cis cyclopropane ring, whereas the meromycolic acids with one trans cyclopropane ring were closely related to the corresponding meromycolic acids with one cis cyclopropane ring. A close relationship between methoxy- and keto-meromycolic acids was also implied. The relationship between the meromycolic acids with a trans double bond and the other meromycolic acids was not clearly revealed, and they did not appear to be immediate substrates for trans cyclopropanation.
\end{abstract}

Keywords: meromycolic acids, CID mass spectrometry, spacing between functional groups

\section{INTRODUCTION}

Mycobacterial mycolic acids, high molecular mass 2alkyl-branched 3-hydroxy fatty acids, are characteristic major lipid components of the cell envelope of mycobacteria. Though they are present in the free lipids of the cell envelope, the majority are esterified to form the terminal [5-mycoloyl- $\beta$-Araf- $(1 \rightarrow 2)-5$-mycoloyl- $\alpha$ $\operatorname{Araf}(1 \rightarrow)]$ units of the arabinogalactan attached to the shape-forming peptidoglycan of the cell envelope (McNeil et al., 1991). According to current models for

\footnotetext{
Abbreviations: CID, collision-induced dissociation; $F A B$, fast atom bombardment; MAC, Mycobacterium avium complex; mu, mass unit measured in $m / z$.
}

the mycobacterial cell envelope, as reviewed by Brennan \& Nikaido (1995), Draper (1998) and Dmitriev et al. (2000), the long hydrocarbon chains of the mycolic acids are arranged in an orderly parallel manner, with the methyl ends facing towards the outside surface of the cell envelope. This mycolate arrangement is considered to form an electron-transparent layer and this arrangement has been demonstrated in electron micrographs of ultra-thin sections of the mycobacterial cell envelope (Paul \& Beveridge, 1992, 1994).

The mycolate layer is known to provide the cells not only with the structural rigidity but also with indispensable functions essential for mycobacterial cells to thrive. Some anti-tuberculosis drugs, such as isoniazid, are known to exhibit their bacteriostatic activity by 
blocking the biosynthesis of mycolic acids. A number of studies have been published on the effects of the component mycolates on the fluidity and permeability of the cell-wall mycolate layer and on the roles of mycolates in the functions of the mycolate layer. The effects of temperature on the fluidity of different mycolates has also been reported (Liu et al., 1996). In a mutant strain of Mycobacterium tuberculosis H37Rv, containing $40 \%$ less cell-wall-linked mycolates than the wild-type, the diffusion rate of glucose through the cellwall layer was shown to be quite high (Jackson et al., 1999). A Mycobacterium smegmatis mutant that produced no mycolates but accumulated arabinogalactanbound meromycolates was hypersensitive to hydrophobic antibiotics such as rifampicin and erythromycin (Liu \& Nikaido, 1999; Wang et al., 2000). Conversely, in an $M$. tuberculosis strain whose cell-wall-linked mycolate consisted solely of $\alpha$-mycolate, the permeation rate through the cell envelope was quite low, implying increased rigidity or solidity of the mycolate layer in the cell envelope of this strain (Dubnau et al., 2000). Recombinant O-methyltransferase-overproducing $M y$ cobacterium bovis BCG and M. tuberculosis $\mathrm{H} 37 \mathrm{Rv}$ strains, whose ketomycolate was completely replaced by the less hydrophilic methoxymycolate, showed poor growth in macrophages in vitro and had a decreased rate of permeation for hydrophilic substances such as glucose, though they were more sensitive than the corresponding wild-type strains to the hydrophilic antibiotic ampicillin (Yuan et al., 1998). With regard to the effect of cyclopropane rings, distal cyclopropanation reportedly increases resistance to killing by $\mathrm{H}_{2} \mathrm{O}_{2}$ (Yuan et al., 1995), whereas proximal cyclopropanation has the effect of decreasing fluidity of the cell wall (George $e t$ al., 1995). The effects of the various functional groups within the mycolates on the functions of the mycolate layer have been described in a review by Barry et al. (1998).

The papers mentioned above attribute, at least partly, the differences observed in host-pathogenicity relationships to the mycolate composition of the infecting mycobacterium and to the structures of or to the nature of the cell envelope mycolate layer of the infecting strain. However, they do not pay much attention to the precise structures of these mycolic acids or to the exact locations of the functional groups within the mycolic acids. The different locations of these functional groups may affect the compactness of the mycolate layer differently and, consequently, may affect its physiological function.

With regard to the biosynthesis of mycolic acids, as shown in a review article by Barry et al. (1998), information has been accumulated through intensive genetic and enzymic investigations. If the biosynthetic relationships between the mycolates are to be clarified, then it is also necessary to know the definite locations of the functional groups. Hence, this study presents the results of a study to characterize the functional groups of type 1 , type 2 and type 3 mycolates, recently described by Watanabe et al. (2001).

\section{METHODS}

Origins of the mycolates analysed. The origins of the mycolates used in this study have been described previously (Watanabe et al., 2001). In addition to the mycolates described by Watanabe et al. (2001), mycolates from Mycobacterium scrofulaceum 4B and Mycobacterium marinum ATCC 927 were extracted and analysed. M. scrofulaceum 4B was obtained from the Research Institute of Tuberculosis (Kiyose, Tokyo) and was cultured in Sauton's medium in a shakeincubator. M. marinum ATCC 927 was obtained from the American Type Culture Collection (Manassas, VA, USA) and was cultured in Sauton's medium. Mycolic acids were extracted from the mycobacteria and were converted to methyl esters, as described previously (Watanabe et al., 2001).

Proton-NMR. These spectra were obtained by using a Bruker DPX $400(400 \mathrm{MHz})$ to analyse the samples, which were in a $\mathrm{CDCl}_{3}$ solution.

MS. Collision-induced dissociation (CID) spectra for meromycolic acids were obtained by using a HX-110A/HX-110A four sector tandem mass spectrometer with an array detector (JEOL, Tokyo, Japan). The accelerating voltage supplied was $10 \mathrm{kV}$, the collision gas used was argon and the collision energy supplied was $2 \mathrm{keV}$. Fast atom bombardment (FAB) was used to desorptively ionize the pre-formed conjugate bases in the basic matrix, diethanolamine + nitrobenzyl alcohol $(1: 1, \mathrm{v} / \mathrm{v})$. The meromycolic acid samples were dissolved in methanol prior to analysis.

TLC. This procedure was performed on pre-coated silica-gel plates (Merck).

Preparation of meromycolic acids. These acids were prepared from methyl mycolates, essentially according to the method described by Krembel \& Etémadi (1966). Briefly, 5-10 mg of mycolic acid methyl ester was placed in a small retort and heated in a sand bath (set at $300{ }^{\circ} \mathrm{C}$ ) for $30 \mathrm{~min}$ at about $1 \mathrm{~mm}$ Hg. The pyrolysate was separated by TLC with hexane/ diethyl ether $(100: 2, \mathrm{v} / \mathrm{v}, \times 2)$ to give meromycolaldehydes and carboxylic acid methyl esters. The ${ }^{1} \mathrm{H}-\mathrm{NMR}$ spectra of the meromycolaldehydes showed signals for the aldehyde proton at 9.77 p.p.m. $(1 \mathrm{H}, \mathrm{t}, J 1.9 \mathrm{~Hz})$ and for the methylene protons adjacent to the aldehyde at 2.42 p.p.m. (double t, $J 7.4$ and $1.9 \mathrm{~Hz}$ ) along with signals for the functional groups. The yield of aldehyde was $60-70 \%$ of the calculated value.

The meromycolaldehyde $(2-5 \mathrm{mg})$ was placed in a screw-cap tube, to which $1 \cdot 0 \mathrm{ml}$ aqueous $\mathrm{NaOH}(10 \%, \mathrm{w} / \mathrm{v})$ and $0.2 \mathrm{ml}$ aqueous $\mathrm{AgNO}_{3}(10 \%, \mathrm{w} / \mathrm{v})$ were added with stirring, at $90^{\circ} \mathrm{C}$. The sealed tube was heated at $90^{\circ} \mathrm{C}$ for $3 \mathrm{~h}$ with continuous stirring. After cooling, the reaction mixture was treated with $2 \mathrm{M} \mathrm{HNO}_{3}$ and extracted with diethyl ether. For purification, the crude meromycolic acid was subjected to TLC with hexane/diethyl ether $(75: 25, \mathrm{v} / \mathrm{v}, \times 2)$. The meromycolic acid gave ${ }^{1} \mathrm{H}$-NMR signals for a very broad carboxylic acid proton at about 10 p.p.m. and for the methylene protons adjacent to the carboxyl group at 2.34 p.p.m. ( $2 \mathrm{H}, \mathrm{t}, J 7.5 \mathrm{~Hz})$, in addition to signals for the functional groups. The yield of meromycolic acid from the meromycolaldehyde was about $80 \%$.

Preparation of hydroxymeromycolic acid. Ketomeromycolic acid (1-3 mg) was dissolved in $3 \mathrm{ml}$ of 2-propanol, to which a drop of saturated $\mathrm{NaBH}_{4}$ solution in ethanol was added. The mixture was left at room temperature for $1 \mathrm{~h}$. Removal of the solvent under reduced pressure, followed by addition of dilute $\mathrm{HCl}$ and extraction with diethyl ether, gave hydroxymeromycolic acid, which was subsequently purified by TLC with hexane/diethyl ether $(75: 25, \mathrm{v} / \mathrm{v}, \times 2)$. The ${ }^{1} \mathrm{H}-\mathrm{NMR}$ spectra 
of hydroxymeromycolic acid gave a pair of signals for the hydroxy-bearing methine protons at 3.50 p.p.m. and 3.46 p.p.m. (both broad signals) for the stereoisomers and a signal for the methylene adjacent to the carboxyl at 2.35 p.p.m. $(2 \mathrm{H}, \mathrm{t}, J 7 \cdot 5 \mathrm{~Hz})$. The yield of the hydroxymeromycolic acid was about $80 \%$.

\section{RESULTS}

In a recent study (Watanabe et al., 2001), methyl mycolates from representative mycobacteria were fractionated into three major types by argentation chromatography; each of these types was characterized by NMR and MS. Type 1 mycolates have no double bonds, type 2 mycolates have a trans double bond and type 3 mycolates have a cis double bond.

In the present study, meromycolic acids were prepared from type 1 , type 2 and type 3 methyl mycolates by pyrolysis and subsequent $\mathrm{Ag}_{2} \mathrm{O}$ oxidation. These meromycolic acids were then analysed by charge-remote fragmentation (CRF) MS to determine the locations of the functional groups within the chain. The categories of the meromycolic acids analysed are summarized in Tables 1-3. The structures of the different types of meromycolic acids are shown in Fig. 1. Basically, CRF of the meromycolates was achieved by high-energy CID, a process considered to proceed through bond cleavage by 1,4-hydrogen elimination and to be independent of the charge (Jensen et al., 1985; Cordero et al., 1994) (CID and its mechanisms and applications have been reviewed by several authors, e.g. Adams \& Songer, 1993; Chen $\&$ Gross, 2000). Fig. 2 shows bond cleavage by 1,4hydrogen elimination in CID, as proposed by Jensen et al. (1985). This technique was developed, in a limited study, for the elucidation of the locations of double bonds in meromycolic acids from Mycobacterium fallax (Savagnac et al., 1989).

The locations of cis and trans double bonds, cis and trans cyclopropane rings, methoxy and keto groups, methyl branches adjacent to the methoxy and keto groups, and trans double bonds and trans cyclopropane rings in meromycolic acid chains were easily determined from their characteristic bond-cleavage profiles. For ketomeromycolic acid assays, the keto group was reduced to hydroxyl to facilitate mass spectral analysis. Functional groups nearer to the carboxy group are referred to as 'proximal', whereas the others are referred to as 'distal' for convenience.

\section{FAB mass spectra}

Figs 3(a), 4(a) and 5(a) show the FAB mass spectra of type $3 \alpha$-meromycolic acid from M. bovis BCG (IV, Fig. 1 and Table 1), of type 2 methoxymeromycolic acid from M. tuberculosis K (VIII, Fig. 1 and Table 2), and of hydroxymeromycolic acid derived from type 1 ketomeromycolic acid from the Mycobacterium avium complex (MAC) bacterium KK41-24 (X and XI, Fig. 1 and Table 3), respectively. Each meromycolic acid was shown to consist of several major homologues with different molecular masses, whose distributions corresponded to the mass distribution of intact mycolic acid methyl esters, as demonstrated by matrix-assisted laser desorption ionization time-of-flight (MALDI-TOF) MS (matrix, 2,5-dihydroxy benzoic acid; reflector mode) performed on a PerSeptive Biosystems Voyager RS system (Watanabe et al., 2001). Representative major ions of the FAB mass spectra for each meromycolic acid were subjected to CID MS.

The FAB mass spectra of type $1 \alpha$-meromycolic acids from Mycobacterium kansasii and the MAC, and of type 1 methoxy- and keto-meromycolic acids from all strains tested, except those from M. tuberculosis H37Ra, consisted of two series of peaks, one for those containing a cis cyclopropane ring and one for those containing a trans cyclopropane ring. The ratio between the peak heights of the most abundant components of the two series in each meromycolic acid differed from species to species, but they were quite similar among those from the strains of the same species. The FAB mass spectra of type 1 methoxy- and keto-meromycolic acids from $M$. tuberculosis $\mathrm{H} 37 \mathrm{Ra}$ and some type 3 meromycolic acids also showed two series of peaks, one each for the components with two and three functional groups.

In the spectra for type $1 \alpha$-meromycolic acids from the $M$. tuberculosis complex, and type 2 and type 3 meromycolic acids of all classes, a series of oddnumbered acid ions were detected, though their contents, as seen in the FAB mass spectra, were normally very small (Figs $3 a$ and $4 a$ ). Odd-numbered acids were, if present, not clearly seen in the spectra of type 1 methoxy- and keto-meromycolic acids, because cis- and trans-cyclopropane-containing isomers formed a series of peaks with 14 mass unit (mu) difference between each peak.

\section{CID mass spectral location of methyl branches}

A methyl branch in the alkyl chain is characterized by a gap of $28 \mathrm{mu}$, as it involves almost simultaneous losses of the methyl and the methine to which the methyl is attached (Tomer et al., 1986). The spacing between $\mathrm{m} / \mathrm{z}$ 225 and $m / z 253$ in the proximal spectra of Fig. 4(b), and the spacing between $m / z 363$ and $m / z 391$ in the proximal spectra of Fig. 5(b) show the locations of their methyl branches.

\section{CID mass spectral location of cis double bonds and cis cyclopropane rings}

Fig. 3(b) shows the CID spectrum of one of the major components of Fig. 3(a), namely the ion fragment of the type $3 \alpha$-meromycolic acid from M. bovis BCG [741 $\left.(M-\mathrm{H})^{-}\right]$, containing one cis cyclopropane ring, proximal to the carboxyl group, and one cis double bond, distal to the carboxyl group (IV, Fig. 1 and Table 1). The areas involving fragmentation of these groups are shown (magnified) and the mode of bond cleavage around the functional groups is illustrated.

The location of the distal cis double bond was shown by a characteristic radical ion at $m / z 474$, caused by the homolytic cleavage of the alkyl carbon linkage, $\alpha$ and $\beta$ to the double bond on the distal side (Crockett et al., 
Table 1. Chain lengths ( $n-m-/$ and $n-n^{\prime}-m-/$ values) for the functional groups in $\alpha$-meromycolic acids

Where two or more homologues were present for one $m / z$, the most abundant one is given in bold italics. In cases where it was difficult to decide which was the major component, all possible combinations are given in bold italics.

\begin{tabular}{|c|c|c|c|c|c|c|c|c|c|c|c|c|c|c|c|}
\hline \multirow[t]{3}{*}{ Origin" } & \multicolumn{8}{|c|}{ Type $1 \mathrm{~m} / \mathrm{z}$} & \multirow[t]{3}{*}{ Origin" } & \multirow{2}{*}{\multicolumn{6}{|c|}{$\begin{array}{l}\text { Type } 2 m / z \\
n-m-l \text { (III) } \\
\end{array}$}} \\
\hline & \multicolumn{7}{|c|}{$n-m-l(\mathrm{I})$} & \multirow{2}{*}{$\begin{array}{c}\begin{array}{c}n-m-l \\
(\mathrm{II})\end{array} \\
853\end{array}$} & & & & & & & \\
\hline & 727 & 755 & 783 & 797 & 811 & 825 & 839 & & & 783 & 797 & 811 & 825 & 839 & 867 \\
\hline M. tuberculosis & & & & & & & & & $\begin{array}{l}\text { M. tuberculosis } \\
\text { Canetti MNC1485 }\end{array}$ & & & $\begin{array}{l}15-13-19 \\
15-15-17\end{array}$ & & $\begin{array}{l}17-13-19 \\
17-15-17\end{array}$ & $17-15-19$ \\
\hline $\begin{array}{l}\text { AoyamaB }(755,783) \\
\text { K (755, 783)† } \\
\text { H37Rv (783) } \\
\text { Canetti MNC1485 } \\
\text { (755, 783)‡ }\end{array}$ & & $11-14-19$ & $13-14-19$ & & $15-14-19$ & & $17-14-19$ & & $\begin{array}{l}\left.\begin{array}{l}\text { MAC } \\
\text { KK41-24 (839) } \\
\text { MNC10 (839) }\end{array}\right\} \\
\begin{array}{l}\text { M. scroflaceum }\end{array}\end{array}$ & & & $15-15-17$ & & $17-15-17$ & $\begin{array}{l}19-15-17 \\
17-17-17\end{array}$ \\
\hline H37Ra $(783)$ & & $\begin{array}{l}17-10-17 \\
15-12-17 \\
13-14-17\end{array}$ & $\begin{array}{l}17-12-17 \\
17-10-19\end{array}$ & & $\begin{array}{l}19-12-17 \\
17-14-17 \\
19-10-19 \\
17-12-19\end{array}$ & & & & B3 $(811)$ & $\begin{array}{l}15-13-17 \\
17-11-17\end{array}$ & $\begin{array}{l}16-13-17 \\
14-15-17\end{array}$ & $17-13-17$ & $16-15-17$ & $\begin{array}{l}17-15-17 \\
19-13-17\end{array}$ & $\begin{array}{l}19-15-17 \\
17-17-17\end{array}$ \\
\hline $\left.\begin{array}{l}\text { M. bovis } \\
\text { MNC8 (783) } \\
\text { MNC27 (783) }\end{array}\right\}$ & & $\begin{array}{l}11-14-19 \\
11-16-17\end{array}$ & $13-14-19$ & & $\begin{array}{l}15-14-19 \\
15-16-17\end{array}$ & & $\begin{array}{l}17-14-19 \\
17-16-17\end{array}$ & & & & & & & & \\
\hline $\begin{array}{l}\text { BCG Tokyo } 172 \\
(755,783)\end{array}$ & & & & & & & & & & & & & & & \\
\hline $\begin{array}{l}\text { M. microti } \\
\text { OV248 }(755,783)\end{array}$ & & $11-14-19$ & $13-14-19$ & & $15-14-19$ & & $17-14-19$ & & & & & & & & \\
\hline M. kansasii & & & & & $17-14-17$ & & $19-12-19$ & $18-14-17$ & & & & & & & \\
\hline 20-01 (811) & & & & & $15-16-17$ & & $19-14-17$ & $18-12-19$ & & & & & & & \\
\hline 304 (811) $\quad\}$ & & & & & $\begin{array}{l}15-14-19 \\
17-12-19\end{array}$ & & $\begin{array}{l}17-14-19 \\
17-16-17\end{array}$ & & & & & & & & \\
\hline MAC & & & & & & & & & & & & & & & \\
\hline $\left.\begin{array}{l}\text { KK41-24 (811) } \\
\text { MNC10 (811) }\end{array}\right\}$ & & & $\begin{array}{l}15-14-17 \\
17-12-17\end{array}$ & $\begin{array}{l}16-14-17 \\
16-12-19\end{array}$ & $\begin{array}{l}17-14-17 \\
17-12-19\end{array}$ & $\begin{array}{l}16-16-17 \\
18-14-17\end{array}$ & $17-16-17$ & $18-14-17$ & & & & & & & \\
\hline M. scroflaceum & & & & & & & & & & & & & & & \\
\hline B3 (811) & & & $15-14-17$ & $16-14-17$ & $17-14-17$ & $16-16-17$ & $17-14-19$ & & & & & & & & \\
\hline & & & $\begin{array}{l}17-12-17 \\
15-12-19\end{array}$ & $16-12-19$ & 17-12-19 & $\begin{array}{l}18-14-17 \\
16-14-19\end{array}$ & $\begin{array}{l}19-12-19 \\
17-16-17\end{array}$ & & & & & & & & \\
\hline M. marinum & & & $17-10-19$ & & & $18-12-19$ & $\begin{array}{l}1 /-16-17 \\
19-14-17\end{array}$ & & & & & & & & \\
\hline ATCC 927 (755) & $11-14-17$ & $13-14-17$ & $\begin{array}{l}15-14-17 \\
15-12-19\end{array}$ & & $\begin{array}{l}17-14-17 \\
17-12-19\end{array}$ & & & & & & & & & & \\
\hline
\end{tabular}


Table 1 (cont.)

\begin{tabular}{|c|c|c|c|c|c|c|c|c|c|c|c|c|c|c|c|c|c|c|}
\hline \multirow[t]{3}{*}{ Origin" } & \multicolumn{18}{|c|}{ Type $3 \mathrm{~m} / \mathrm{z}$} \\
\hline & \multicolumn{3}{|c|}{$n-m-l$ (IV) } & \multicolumn{11}{|c|}{$n-m-l(\mathrm{~V})$} & \multicolumn{4}{|c|}{$n-n^{\prime}-m-l\left(\mathrm{~V}^{\prime}\right)$} \\
\hline & 741 & 769 & 797 & 713 & 727 & 741 & 755 & 769 & 783 & 797 & 811 & 825 & 839 & 853 & & 781 & 809 & \\
\hline \multicolumn{19}{|l|}{ M. tuberculosis } \\
\hline \multirow{2}{*}{\multicolumn{19}{|c|}{$\begin{array}{l}\text { K }(769) \\
2668 / 92(741) \mathbb{S}\end{array}$}} \\
\hline & & & & & & & & & & & & & & & & & & \\
\hline $\begin{array}{l}\text { Canetti MNC1485 } \\
(769) \|\end{array}$ & & & & $\begin{array}{l}9-14-19 \\
9-16-17\end{array}$ & $\begin{array}{l}10-14-19 \\
10-16-17\end{array}$ & $11-14-19$ & $\begin{array}{l}12-14-19 \\
12-16-17\end{array}$ & $13-14-19$ & $14-14-19$ & $15-14-19$ & $16-14-19$ & $17-14-19$ & & & & & & \\
\hline \multirow[t]{3}{*}{$\mathrm{H} 37 \mathrm{Ra}(769, \underline{809})$} & & & & & & $\begin{array}{l}15-12-17 \\
17-10-17\end{array}$ & $16-12-17$ & $\begin{array}{l}17-12-17 \\
19-10-17\end{array}$ & $\begin{array}{l}19-10-19 \\
19-12-17\end{array}$ & & & & & & $11-6-$ & $10-17$ & 13-6- & $10-17$ \\
\hline & & & & & & & & $17-10-9$ & & & & & & & $13-4-$ & $12-15$ & $15-4-$ & $12-15$ \\
\hline & & & & & & & & $19-8-19$ & & & & & & & & & & \\
\hline \multirow{2}{*}{\multicolumn{19}{|c|}{$\begin{array}{l}\text { M. bovis } \\
\text { BCG Tokyo } 172(769)\end{array}$}} \\
\hline & & & & & & & & & & & & & & & & & & \\
\hline $\begin{array}{l}\text { M. microti } \\
\text { OV248 (769) }\end{array}$ & $11-14-19$ & $13-14-19$ & $15-14-19$ & & & & & & & & & & & & & & & \\
\hline \multicolumn{19}{|l|}{ MAC } \\
\hline \multirow{2}{*}{$\left.\begin{array}{l}\text { KK41-24 (797) } \\
\text { MNC10 (769) }\end{array}\right\}$} & & & & & & $13-14-17$ & $14-14-17$ & $15-14-17$ & $16-14-17$ & $17-14-17$ & $18-14-17$ & $19-14-17$ & $18-16-17$ & $19-16-17$ & & & & \\
\hline & & & & & & $10-1+2-1 / 4$ & & $15-12-19$ & $16-12-19$ & $17-12-19$ & $18-12-19$ & $19-12-19$ & & $19-14-19$ & & & & \\
\hline \multicolumn{19}{|l|}{ M. marinarum } \\
\hline \multirow{2}{*}{ ATCC 927 (769) } & & & & & $12-14-17$ & $13-14-17$ & $14-14-17$ & $15-14-17$ & $16-14-17$ & $17-14-17$ & & & & & & & & \\
\hline & & & & & $14-12-17$ & $15-12-17$ & & $15-12-19$ & $16-12-19$ & $17-12-19$ & & & & & & & & \\
\hline
\end{tabular}

* Numbers in parentheses indicate the most abundant $m / z$ value of the series. Underlined numbers in parentheses are for the major $m / z$ value of the three-group-containing series. $\dagger m / z 783$ contains a small amount of 13-16-17.

$\neq m / z 811$ contains a small amount of 17-12-19.

$\$ m / z 769$ contains $15-12-19$. Major $m / z$ was 741

$\| m / z 741$ includes $11-16-17, m / z 755$ includes $14-12-19$ and $m / z 769$ includes $15-12-19$ 
Table 2. Chain lengths ( $n-m-l$ and $n-n^{\prime}-m-l$ values) for the functional groups in methoxymeromycolic acids

Where two or more homologues were present for one $m / z$, the most abundant one is given in bold italics. In cases where it was difficult to decide which was the major component, all possible combinations are given in bold italics.

\begin{tabular}{|c|c|c|c|c|c|c|c|c|c|c|c|c|c|c|c|}
\hline \multirow[t]{3}{*}{ Origin" } & \multicolumn{15}{|c|}{ Type $1 \mathrm{~m} / \mathrm{z}$} \\
\hline & \multicolumn{6}{|c|}{$n-m-l(\mathrm{VI})$} & \multicolumn{5}{|c|}{$n-m-l(\mathrm{VII})$} & \multicolumn{4}{|c|}{$n-n^{\prime}-m-l\left(\mathrm{VI}^{\prime}\right)$} \\
\hline & 815 & 843 & 871 & 899 & 927 & 955 & 857 & 885 & 913 & 941 & 969 & 883 & & 911 & \\
\hline 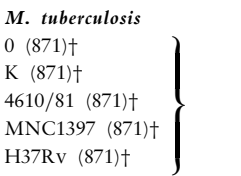 & & & $17-16-17$ & $17-18-17$ & & & & & $18-16-17$ & & & & & & \\
\hline Canetti MNC1485 (871)‡ & & & $17-16-17$ & $19-16-17$ & $\begin{array}{l}21-16-17 \\
19-18-17\end{array}$ & $\begin{array}{l}21-18-17 \\
23-16-17\end{array}$ & & & & $20-16-17$ & $22-16-17$ & & & & \\
\hline $\mathrm{H} 37 \mathrm{Ra}(843, \underline{883})$ & $\begin{array}{l}17-14-15 \\
17-12-17\end{array}$ & $\begin{array}{l}19-14-15 \\
19-12-17\end{array}$ & $\begin{array}{l}19-14-17 \\
21-12-17 \\
19-16-15 \\
21-14-15\end{array}$ & $\begin{array}{l}21-14-17 \\
23-12-17 \\
21-16-15 \\
23-14-15\end{array}$ & & & & & & & & $\left.\begin{array}{r}11-12- \\
13-10- \\
15-8-\end{array}\right]$ & $\begin{array}{l}10-15 \\
8-17 \\
8-17\end{array}$ & $\left.\begin{array}{r}13-12- \\
15-10- \\
17-8-\end{array}\right]$ & $\begin{array}{l}10-15 \\
8-17 \\
8-17\end{array}$ \\
\hline & & & & & & & & & & & & \begin{tabular}{r|}
$11-10-$ \\
$13-8-$ \\
$15-6-$
\end{tabular} & $\begin{array}{l}12-15 \\
10-17 \\
10-17\end{array}$ & \begin{tabular}{r|}
$13-10-$ \\
$15-8-$ \\
$17-6-$
\end{tabular} & $\begin{array}{l}12-15 \\
10-17 \\
10-17\end{array}$ \\
\hline $\begin{array}{l}\text { M. bovis } \\
\text { MNC8 (871)† } \\
\text { BCG Tokyo } 172(871)\end{array}$ & & & $17-16-17$ & $17-18-17$ & & & & & & & & & & & \\
\hline $\begin{array}{l}\text { M. microti } \\
\text { OV248 (871) }\end{array}$ & & $15-16-17$ & $\begin{array}{l}17-16-17 \\
17-14-19\end{array}$ & $\begin{array}{l}17-18-17 \\
17-16-19\end{array}$ & & & & & $18-16-17$ & & & & & & \\
\hline $\left.\begin{array}{l}\text { M. kansasii } \\
20-01(899) \mathbb{S} \\
304(899) \mathbb{S} \\
429 \\
(871) \mathbb{S}\end{array}\right\}$ & & $\begin{array}{l}17-16-15 \\
17-14-17\end{array}$ & $\begin{array}{l}17-16-17 \\
19-14-17 \\
17-18-15 \\
19-16-15\end{array}$ & $19-16-17$ & $21-16-17$ & & $16-14-17$ & $18-14-17$ & $18-16-17$ & $20-16-17$ & & & & & \\
\hline
\end{tabular}


Table 2 (cont.)

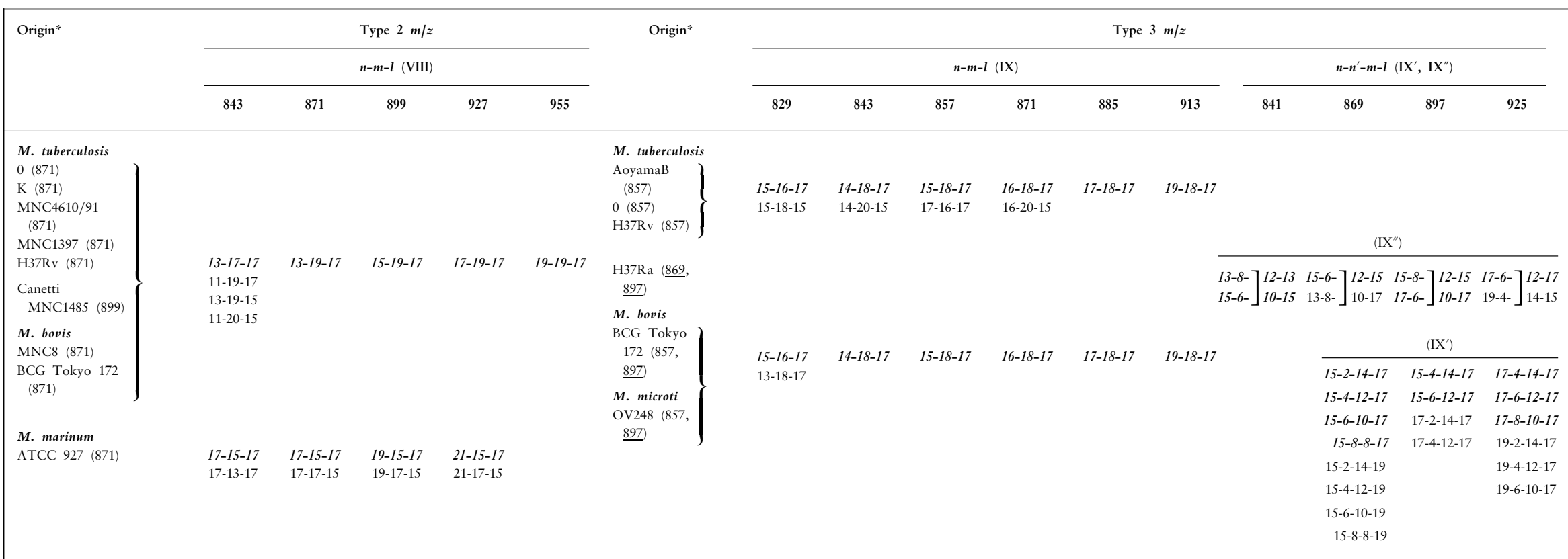

* Numbers in parentheses indicate the most abundant $m / z$ value of the series. Underlined numbers in parentheses are for the major $m / z$ value of the three-group-containing series. $\dagger$ The most abundant $m / z$ of the trans series is 913 . In those samples with no $\dagger, \ddagger$ or $\mathbb{\$}$, the trans content is small or scarce.

¥ The most abundant $m / z$ of the trans series is 969 .

$\mathbb{\$}$ The most abundant $m / z$ of the trans series is $913 / 941$. 
Table 3. Chain lengths ( $n-m-I$ and $n-n^{\prime}-m-I$ values) for the functional groups in ketomeromycolic acids

Where two or more homologues were present for one $m / z$, the most abundant one is given in bold italics. In cases where it was difficult to decide which was the major component, all possible combinations are given in bold italics.

\begin{tabular}{|c|c|c|c|c|c|c|c|c|c|c|c|c|c|c|c|c|c|c|}
\hline \multirow[t]{3}{*}{ Origin* } & \multicolumn{18}{|c|}{ Type $1 \mathrm{~m} / \mathrm{z}$} \\
\hline & \multicolumn{5}{|c|}{$n-m-l(\mathrm{X})$} & \multicolumn{5}{|c|}{$n-m-l(\mathrm{XI})$} & & \multicolumn{7}{|c|}{$n-n^{\prime}-m-l\left(\mathrm{X}^{\prime}\right)$} \\
\hline & 799 & 827 & 855 & 883 & 911 & 841 & 869 & 897 & 925 & 953 & & 839 & & 867 & & 895 & & 923 \\
\hline \multicolumn{19}{|l|}{ M. tuberculosis } \\
\hline \multicolumn{19}{|l|}{ O (897)t‡ } \\
\hline $\begin{array}{l}\text { K }(897) \neq \\
4610 / 81\end{array}$ & $11-16-19$ & 13-18-17 & $15-18-17$ & $17-18-17$ & 19-18-17 & $14-18-15$ & $16-18-15$ & $16-18-17$ & $18-18-17$ & $20-18-17$ & & & & & & & & \\
\hline $\begin{array}{l}\text { 4610/81 (897)‡ } \\
\text { MNC1397 (897)‡ }\end{array}$ & $11-18-17$ & $15-16-17$ & $17-16-17$ & $17-20-15$ & & $14-16-17$ & $16-16-17$ & & & $20-10-17$ & & & & & & & & \\
\hline H37Rv (897) +ł & & 15-14-19 & $15-20-15$ & & & & & & & & & & & & & & & \\
\hline $\begin{array}{l}\text { Canetti MNC1485 } \\
(897) \dagger \neq\end{array}$ & & 13-16-19 & $17-18-15$ & & & & & & & & & & & & & & & \\
\hline \multirow[t]{10}{*}{$\mathrm{H} 37 \mathrm{Ra}(855, \underline{895}) \dagger$} & $17-14-15$ & $19-14-15$ & $19-16-15$ & $19-16-17$ & & & & & & & & & & & $3-12-1$ & $10-15$ & $15-10-7$ & $12-15$ \\
\hline & $17-12-17$ & $19-12-17$ & $21-14-15$ & $21-14-17$ & & & & & & & ${ }^{13-10-}$ & 8-15 & $11-12-$ & $10-15$ & $15-12-1$ & $\left.\right|^{10-13}$ & $10-10-$ & $12-150$ \\
\hline & & & 19-14-17 & $23-12-17$ & & & & & & & $15-8-$ & $6-17$ & $13-10-$ & $8-17$ & $15-10-$ & $8-17$ & $17-8-$ & $10-17$ \\
\hline & & & $21-12-17$ & 19-18-15 & & & & & & & $17-6-$ & $6-17$ & $15-8-$ & & $17-8-$ & $8-17$ & & \\
\hline & & & & $\begin{array}{l}21-16-15 \\
23-14-15\end{array}$ & & & & & & & & & $15-8-$ & $8-17$ & & & & \\
\hline & & & & & & & & & & & $13-8-$ & $10-15$ & & & $13-10-$ & $12-15$ & & \\
\hline & & & & & & & & & & & 15-6- & $8-17$ & $11-10$ & $12-15$ & $15-8-$ & $10-17$ & & \\
\hline & & & & & & & & & & & $17-4-$ & $8-17$ & $13-8-$ & $10-17$ & $17-6-$ & $10-17$ & & \\
\hline & & & & & & & & & & & & & $15-6-$ & $10-17$ & & & & \\
\hline & & & & & & & & & & & & & $17-4-$ & $10-17$ & & & & \\
\hline \multirow{2}{*}{\multicolumn{19}{|c|}{ M. bovis }} \\
\hline MNC8 (897)†‡ & & & & & & & & & & & & & & & & & & \\
\hline BCG Tokyo 172 & $11-16-19$ & $13-18-17$ & $15-18-17$ & $17-18-17$ & $19-18-17$ & $14-18-15$ & $16-18-15$ & $16-18-17$ & $18-18-17$ & $20-18-17$ & & & & & & & & \\
\hline$(855) \S$ & $11-18-17$ & $15-16-17$ & $17-16-17$ & $17-20-15$ & & $14-16-17$ & $16-16-17$ & & & & & & & & & & & \\
\hline M. microti & & 15-14-19 & $15-20-15$ & & & & & & & & & & & & & & & \\
\hline OV248 $(855)+\mathbb{S} \|$ & & 13-16-19 & 17-18-15 & & & & & & & & & & & & & & & \\
\hline \multicolumn{19}{|l|}{ M. kansasii } \\
\hline 20-01(897)‡ ] & & & $17-18-15$ & $17-20-15$ & $19-20-15$ & & $16-18-15$ & $18-18-15$ & $20-18-15$ & $20-18-17$ & & & & & & & & \\
\hline $304(897)+\neq$ & & & $17-16-17$ & $19-18-15$ & $19-18-17$ & & $18-16-15$ & $18-16-17$ & $20-16-17$ & $20-20-15$ & & & & & & & & \\
\hline \multirow[t]{2}{*}{$429(897)+\ddagger$} & & & & $17-18-17$ & & & $16-16-17$ & & & & & & & & & & & \\
\hline & & & & $19-16-17$ & & & $18-14-17$ & & & & & & & & & & & \\
\hline \multicolumn{19}{|l|}{ MAC } \\
\hline KK41-24 (897)† \ & & $17-16-15$ & $17-18-15$ & $19-18-15$ & & $16-16-15$ & $18-16-15$ & $18-16-17$ & $20-16-17$ & & & & & & & & & \\
\hline \multirow{3}{*}{ MNC10 (897) $\neq\}$} & & & $19-16-15$ & $19-16-17$ & & $16-14-17$ & 18-14-17 & $18-18-15$ & & & & & & & & & & \\
\hline & & & $17-16-17$ & & & & & & & & & & & & & & & \\
\hline \multirow{2}{*}{\multicolumn{19}{|c|}{ M. scroflaceum }} \\
\hline & & & & & & & & & & & & & & & & & & \\
\hline B3 $(869) \ddagger$ & & $17-16-15$ & $19-16-15$ & $19-18-15$ & & $16-16-15$ & $18-16-15$ & $20-16-15$ & & & & & & & & & & \\
\hline
\end{tabular}




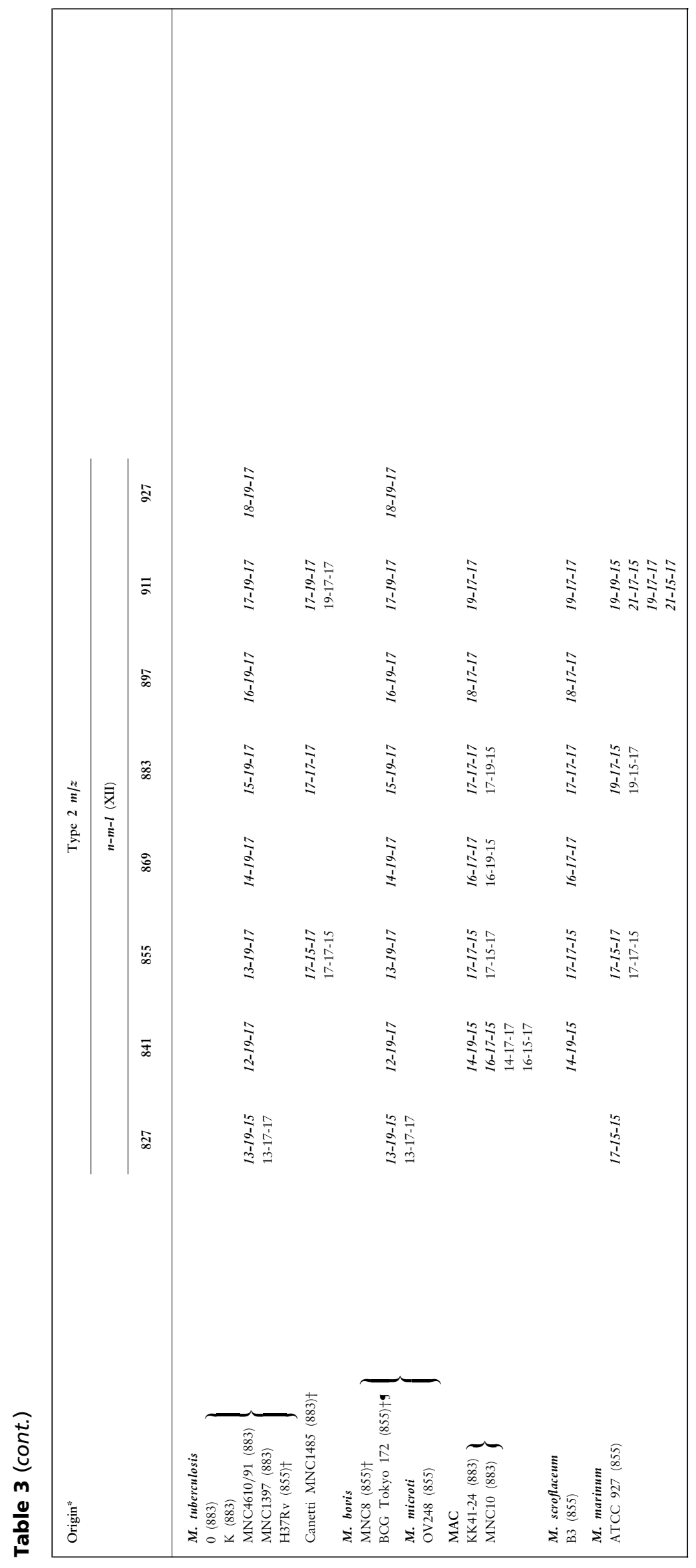


Table 3 (cont.)

\begin{tabular}{|c|c|c|c|c|c|c|c|c|c|c|c|c|c|c|c|c|}
\hline \multirow[t]{3}{*}{ Origin" } & \multicolumn{16}{|c|}{ Type $3 \mathrm{~m} / \mathrm{z}$} \\
\hline & \multicolumn{12}{|c|}{$n-m-l$ (XIII) } & \multicolumn{4}{|c|}{$n-n^{\prime}-m-l\left(\mathrm{XIII}^{\prime}, \mathrm{XIII}^{\prime}\right)$} \\
\hline & 743 & 757 & 771 & 785 & 799 & 813 & 827 & 841 & 855 & 869 & 883 & 897 & 825 & 853 & 881 & 909 \\
\hline \multicolumn{17}{|l|}{ M. tuberculosis } \\
\hline \multirow[t]{4}{*}{ H37Ra $(\underline{881}) \dagger$} & & & & & & & & & & & & & \multicolumn{4}{|c|}{$\left(\mathrm{XIII}^{\prime \prime}\right)$} \\
\hline & & & & & & & & & & & & & $11-10-710-15$ & $13-8-712-15$ & $15-8-712-15$ & $15-10-7^{12-15}$ \\
\hline & & & & & & & & & & & & & $13-8-]_{8-17}^{8}$ & $15-6-]_{10-17}$ & $17-6-]_{10-17}$ & \begin{tabular}{l|l}
$17-8-$ & $10-17$
\end{tabular} \\
\hline & & & & & & & & & & & & & & & & \begin{tabular}{l|l|l}
$19-6-$ & $10-17$
\end{tabular} \\
\hline \multirow{10}{*}{$\begin{array}{l}\text { M. bovis } \\
\text { BCG Tokyo } \\
172(841, \underline{881}) \dagger\end{array}$} & & & & & & & & & & & & & & & & \\
\hline & & & $10-18-17$ & $11-18-17$ & $12-18-17$ & $13-18-17$ & & $15-18-17$ & $16-18-17$ & $17-18-17$ & & $\begin{array}{l}19-18-17 \\
17-20-17\end{array}$ & & & & III') \\
\hline & & & & & & & & & & & & & & & $15-10-8-17$ & $17-4-14-17$ \\
\hline & & & & & & & & & & & & & & & $15-8-10-17$ & $17-6-12-17$ \\
\hline & & & & & & & & & & & & & & & $15-6-12-17$ & $17-8-10-17$ \\
\hline & & & & & & & & & & & & & & & $15-4-14-17$ & $17-10-8-17$ \\
\hline & & & & & & & & & & & & & & & & $17-4-16-15$ \\
\hline & & & & & & & & & & & & & & & & $17-6-14-15$ \\
\hline & & & & & & & & & & & & & & & & $17-8-12-15$ \\
\hline & & & & & & & & & & & & & & & & $17-10-10-15$ \\
\hline \multicolumn{17}{|l|}{ MAC } \\
\hline $\begin{array}{l}\text { KK41-24 (869) } \\
M N C 10(869)\end{array}$ & & & & & & & & $17-16-17$ & $18-16-17$ & $19-16-17$ & $20-16-17$ & $21-16-17$ & & & & \\
\hline
\end{tabular}

*Numbers in parentheses indicate the most abundant $m / z$ value of the series. Underlined numbers in parentheses are for the major $m / z$ value of the three-group-containing series. The $m / z$ values given are for the ketomeromycolic acids.

† Samples also analysed as hydroxymeromycolic acids.

$\neq$ Major $m / z$ of the cis series was 855 .

$\$$ Major $\mathrm{m} / \mathrm{z}$ of the trans series was 897 . In those samples with no $\mathbb{S}$, the trans content was small or scarce.

$\| m / z 855$ contains $15-16-19$ and $17-14-19$.

I $m / z 827$ contains $13-15-19$. 


\section{$a$-Meromycolic acids}

Type-1

$$
\text { (II) HOOC- } \left.\left(\mathrm{CH}_{2}\right)_{n} \underset{\sim}{\sim}\left(\mathrm{CH}_{2}\right)_{m}\left(\mathrm{CH}_{2}\right)_{l}-\mathrm{CH}_{3}\right)-\left(\mathrm{CH}_{2}\right)_{m}\left(\mathrm{CH}_{2}\right)_{l} \mathrm{CH}_{3}
$$

Type-2

(III) $\mathrm{HOOC}-\left(\mathrm{CH}_{2}\right)_{n}-\mathrm{CH}\left(\mathrm{CH}_{3}\right)^{\prime}, \mathrm{CH}=\mathrm{CH}^{\prime}\left(\mathrm{CH}_{2}\right)_{m} /\left(\mathrm{CH}_{2}\right)_{i} \mathrm{CH}_{3}$

Type-3

(IV) $\mathrm{HOOC}-\left(\mathrm{CH}_{2}\right)_{\nearrow} \succ\left(\mathrm{CH}_{2}\right)_{m} \searrow_{\mathrm{CH}=\mathrm{CH}}-\left(\mathrm{CH}_{2}\right)_{l}-\mathrm{CH}_{3}$

(V) $\mathrm{HOOC}-\left(\mathrm{CH}_{2}\right)_{\mathrm{r}}{ }_{\mathrm{CH}=\mathrm{CH}} /\left(\mathrm{CH}_{2}\right)_{m} \searrow /\left(\mathrm{CH}_{2}\right)_{l}-\mathrm{CH}_{3}$

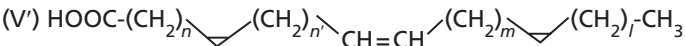

\section{Methoxymeromycolic acids}

Type-1

(VI) $\mathrm{HOOC}-\left(\mathrm{CH}_{2}\right) \backslash\left(\mathrm{CH}_{2}\right)_{m}-\mathrm{CH}\left(\mathrm{OCH}_{3}\right)-\mathrm{CH}\left(\mathrm{CH}_{3}\right)-\left(\mathrm{CH}_{2}\right)_{-}-\mathrm{CH}_{3}$

$\left(\mathrm{VI} \mathrm{I}^{\prime}\right) \mathrm{HOOC}-\left(\mathrm{CH}_{2}\right)_{n} \rightleftharpoons\left(\mathrm{CH}_{2}\right)_{n^{\prime}} \rightleftharpoons\left(\mathrm{CH}_{2}\right)_{m}-\mathrm{CH}\left(\mathrm{OCH}_{3}\right)-\mathrm{CH}\left(\mathrm{CH}_{3}\right)-\left(\mathrm{CH}_{2}\right)_{1}-\mathrm{CH}_{3}$

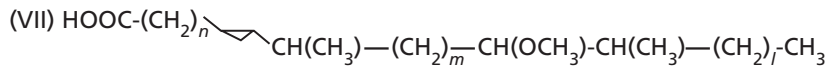

Type-2

(VIII) $\mathrm{HOOC}-\left(\mathrm{CH}_{2}\right)_{n}-\mathrm{CH}\left(\mathrm{CH}_{3}\right)-\mathrm{CH}=\mathrm{CH} \backslash\left(\mathrm{CH}_{2}\right)_{m}-\mathrm{CH}\left(\mathrm{OCH}_{3}\right)-\mathrm{CH}\left(\mathrm{CH}_{3}\right)-\left(\mathrm{CH}_{2}\right)_{l}-\mathrm{CH}_{3}$

Type-3

(IX) $\mathrm{HOOC}-\left(\mathrm{CH}_{2}\right)_{n}-\mathrm{CH}=\mathrm{CH}^{-}\left(\mathrm{CH}_{2}\right)-\mathrm{m}$ CH$\left(\mathrm{OCH}_{3}\right)-\mathrm{CH}\left(\mathrm{CH}_{3}\right)-\left(\mathrm{CH}_{2}\right)_{i}-\mathrm{CH}_{3}$

(IX') $\mathrm{HOOC}-\left(\mathrm{CH}_{2}\right)_{\pi}{ }_{\mathrm{CH}}=\mathrm{CH}^{\prime} /\left(\mathrm{CH}_{2}\right)_{n^{\prime}} \rightleftharpoons\left(\mathrm{CH}_{2}\right)-\mathrm{CH}\left(\mathrm{OCH}_{3}\right)-\mathrm{CH}\left(\mathrm{CH}_{3}\right)-\left(\mathrm{CH}_{2}\right)_{l}-\mathrm{CH}_{3}$

(IX") $\mathrm{HOOC}-\left(\mathrm{CH}_{2}\right)_{n} \downarrow\left(\mathrm{CH}_{2}\right)^{\prime} \mathrm{CH}=\mathrm{CH}^{\prime}\left(\mathrm{CH}_{2}\right)_{m}-\mathrm{CH}\left(\mathrm{OCH}_{3}\right)-\mathrm{CH}\left(\mathrm{CH}_{3}\right)-\left(\mathrm{CH}_{2}\right)_{l}-\mathrm{CH}_{3}$

\section{Ketomeromycolic acids}

Type-1

Type-3

(X) $\mathrm{HOOC}-\left(\mathrm{CH}_{2}\right)_{n}\left(\mathrm{CH}_{2}\right)_{m}-\mathrm{CO}-\mathrm{CH}\left(\mathrm{CH}_{3}\right)-\left(\mathrm{CH}_{2}\right)_{l}-\mathrm{CH}_{3}$

(XIII) $\mathrm{HOOC}-\left(\mathrm{CH}_{2}\right)_{\lambda}{ }_{\mathrm{CH}=\mathrm{CH}} /\left(\mathrm{CH}_{2}\right)-\mathrm{CO}-\mathrm{CH}\left(\mathrm{CH}_{3}\right)-\left(\mathrm{CH}_{2}\right)_{i}-\mathrm{CH}_{3}$

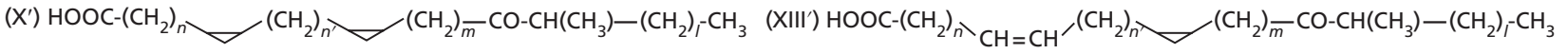

(XI) HOOC- $\left(\mathrm{CH}_{2}\right) \backslash \mathrm{CH}\left(\mathrm{CH}_{3}\right)-\left(\mathrm{CH}_{2}\right)_{m}-\mathrm{CO}-\mathrm{CH}\left(\mathrm{CH}_{3}\right)-\left(\mathrm{CH}_{2}\right)_{l}-\mathrm{CH}_{3}$

$\left(\mathrm{XIII}^{\prime}\right) \mathrm{HOOC}-\left(\mathrm{CH}_{2}\right)_{n}-\left(\mathrm{CH}_{2}\right)_{n}>\mathrm{CH}=\mathrm{CH} /\left(\mathrm{CH}_{2}\right)_{m}-\mathrm{CO}-\mathrm{CH}\left(\mathrm{CH}_{3}\right)-\left(\mathrm{CH}_{2}\right)_{l}-\mathrm{CH}_{3}$

Type-2

(XII) HOOC- $\left(\mathrm{CH}_{2}\right)_{n}-\mathrm{CH}\left(\mathrm{CH}_{3}\right)$

$\left(\mathrm{CH}_{2}\right)-\mathrm{CO}-\mathrm{CH}\left(\mathrm{CH}_{3}\right)-\left(\mathrm{CH}_{2}\right)_{l}-\mathrm{CH}_{3}$

Fig. 1. Chemical structures for $\alpha$-meromycolic acids, methoxymeromycolic acids and ketomeromycolic acids. The numbers in parentheses refer to those shown in Tables 1-3. The $n, m$ and / portion of each acid is indicated.

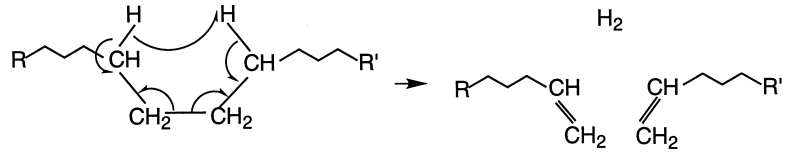

Fig. 2. Schematic drawing showing the 1,4-hydrogenelimination bond cleavage utilized in CID MS.

1990), and by a pair of ions of low intensities at $\mathrm{m} / \mathrm{z}$ 445/447. The location of the proximal cis cyclopropane was shown by a characteristic gap of $40 \mathrm{mu}$ between $m / z 197$ and $m / z 237$ (Tomer et al., 1986) along with two pairs of fragment ions at $m / z 209 / 211$ and $m / z$ $223 / 225$, due to the cleavage of the bonds in the cyclopropane ring.

\section{CID mass spectral location of methoxy groups and trans double bonds}

Fig. 4(b) shows the CID spectrum of one of the major peaks of Fig. 4(a), namely the ion fragment of the type 2 methoxymeromycolic acid from M. tuberculosis K [871, $(M-\mathrm{H})^{-}$] containing a distal methoxy group and a proximal trans double bond, with magnification of the areas involving fragmentation of the functional groups (VIII, Fig. 1 and Table 2). The mode of cleavage around the functional groups is also illustrated. The fragment profile produced by the bond cleavage at and near the trans double bond was practically the same as that of the proximal cis double bond in Fig. 3(b), with a radical ion at $m / z 294$ and a pair of fragment ions of low intensities at $m / z 265 / 267$. The gap of $28 \mathrm{mu}$ between the ion at $m / z 253$, caused by the cleavage of the double bond/ alkyl carbon linkage on the proximal side, and the abundant ion at $m / z 225$ implied that the methyl branch adjacent to the trans double bond was on the proximal side.

The location of the methoxy group was shown by an ion at $m / z 587$, caused by 1,4 -elimination of methanol. The spectrum was characterized by the presence of a series of fragment ions at $m / z 587$ (major), $m / z 601, m / z 615$, $m / z 629, m / z 643$ and $m / z 657$, caused by CID involving the elimination of methanol, demonstrating that CID does not necessarily require the 1,4-elimination mechanism. The fragment caused by removal of methanol was at $m / z 587$ and not at $m / z 573$, demonstrating that 


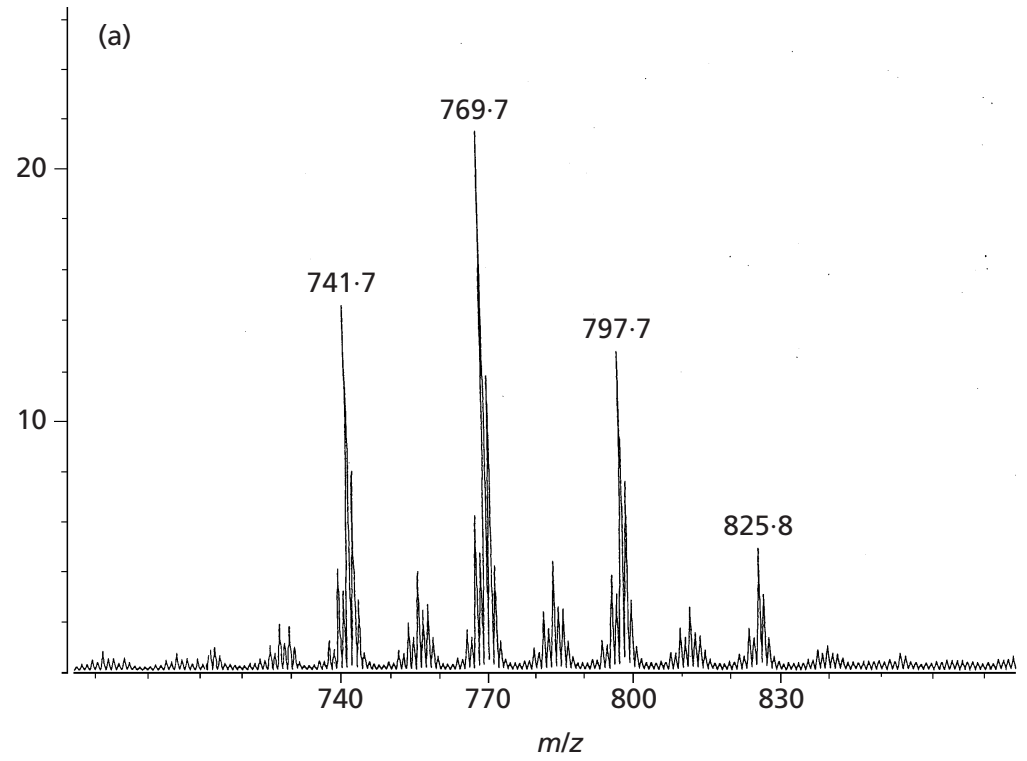

(b)
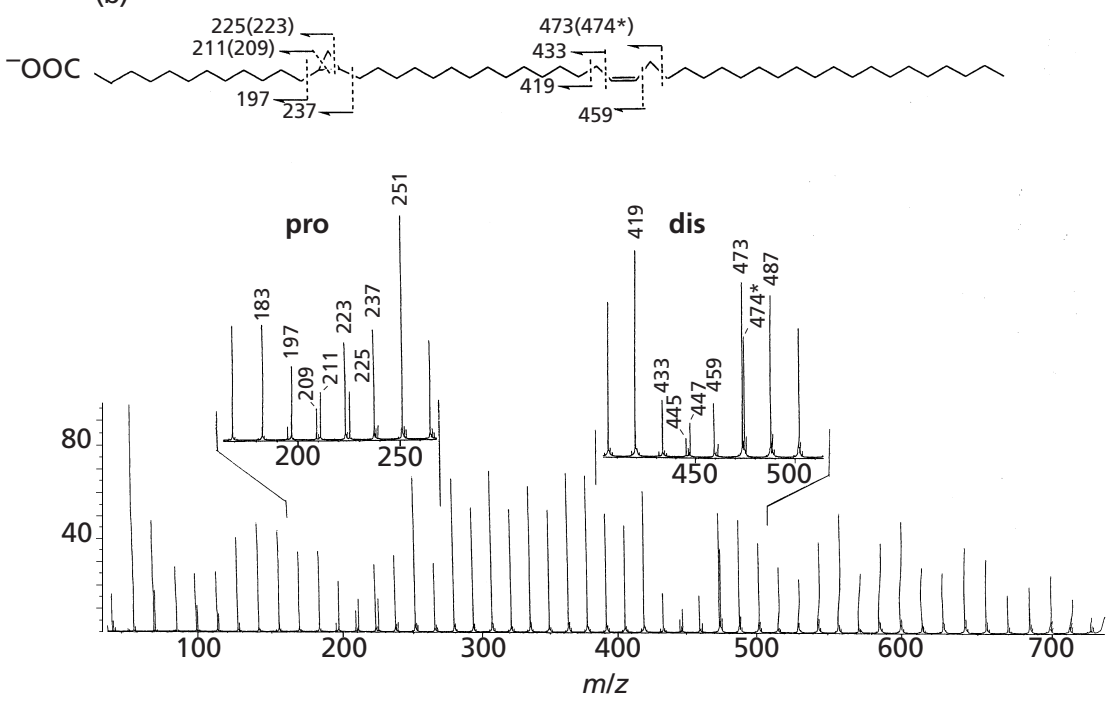

Fig. 3. (a) $F A B$ mass spectrum of type $3 \alpha$ meromycolic acid from $M$. bovis BCG Tokyo, with one cis double bond and one cis cyclopropane ring. (b) CID spectrum of one of the major ion fragments [741 $(\mathrm{M}-\mathrm{H})^{-} ; n-$ $m-I=11-14-19]$ from (a), with magnification of the areas involving cleavage of the functional groups and an illustration of the mode of bond cleavage. pro, Proximal vicinity of the cis cyclopropane ring; dis, distal vicinity of the cis double bond. the methyl group adjacent to the methoxy group was on the distal side. The fragment at $m / z 575$ was caused by CID through the elimination of methane.

\section{CID mass spectral location of hydroxy groups and trans cyclopropane rings}

Fig. 5(b) shows the CID spectrum of one of the major peaks of Fig. 5(a), namely the peak from the hydroxymeromycolic acid containing a proximal trans cyclopropane ring and a distal hydroxy group $\left[927(M-\mathrm{H})^{-}\right]$, with magnification of the areas involving fragmentation of these groups. This hydroxymeromycolic acid was derived from type 1 ketomeromycolic acid from MAC KK41-24 (XI, Fig. 1 and Table 3). An illustration of the mode of bond cleavage around the functional groups is also given.

The location of the trans cyclopropane ring was shown by a characteristic spacing of $40 \mathrm{mu}$ between $\mathrm{m} / z 323$ and $m / z 363$, as was seen for the spectrum of components with a cis cyclopropane ring in Fig. 3(b) proximal. The fragment ion at $m / z 363 \mathrm{had}$ a stronger intensity than the corresponding one in the spectrum of a cis cyclopropane compound, as reported by Tomer $e t$ al. (1986). The two pairs of ions due to the cyclopropane ring bond cleavage, observed in the spectrum of a cis cyclopropane ring (Fig. 3b, proximal), were generally less obvious in the spectrum of trans cyclopropane ring compounds. A gap of $28 \mathrm{mu}$, observed between the ion at $m / z 363$, produced by cleavage of the cyclopropane/ alkyl carbon on the distal side, and the ion at $m / z$ 391, demonstrated the presence of a methyl group on the distal side of the cyclopropane ring.

The location of the hydroxy group was revealed by an ion at $m / z 657$, due to $\mathrm{H}_{2} \mathrm{O}$ loss (Tomer et al., 1986). As was the case for the distal methoxy group (Fig. 4b), the spectrum was characterized by a series of ions at $\mathrm{m} / z$ 657, $m / z 685$ and $m / z 699$, produced by CID through 

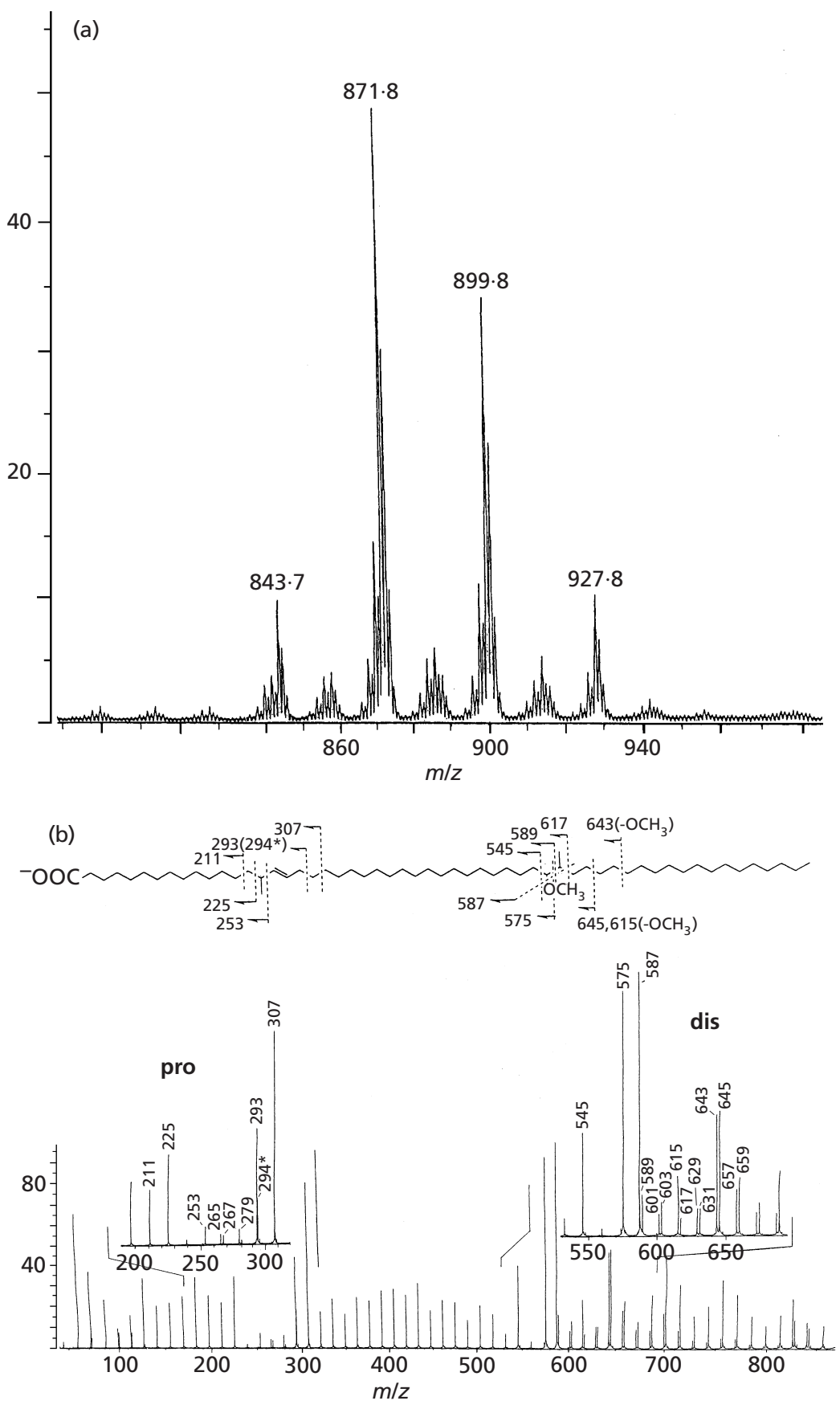

Fig. 4. (a) $F A B$ mass spectrum of type 2 methoxymeromycolic acid from $M$. tuberculosis $\mathrm{K}$, with one trans double bond and one methoxy group. (b) CID spectrum of one of the major ion fragments [871 $(\mathrm{M}-\mathrm{H})^{-}$; $n-m-I=13-19-17]$ from (a), with magnification of the areas involving cleavage of the functional groups and an illustration of the mode of bond cleavage. pro, Proximal vicinity of the trans double bond; dis, distal vicinity of the methoxy group. the elimination of $\mathrm{H}_{2} \mathrm{O}$, again showing that CID does not necessarily require the 1,4 -elimination mechanism. That the fragment ion caused by the removal of $\mathrm{H}_{2} \mathrm{O}$ was at $m / z 657$ and not at $m / z 643$, with no detectable ion at $m / z 659$, provided evidence that the adjacent methyl group was on the distal side of the hydroxy group.

\section{CID mass spectral location of keto groups}

Fig. 5(c) shows part of the spectrum of the corresponding component $\left[925(\mathrm{M}-\mathrm{H})^{-}\right]$of ketomeromycolic acid from MAC KK41-24 (XI, Fig. 1 and Table 3), from which the hydroxymeromycolic acid (whose spectral features were discussed above) was prepared, and the fragmentation profile around the keto group.

Both the keto group and the adjacent methyl/methine gave a gap of $28 \mathrm{mu}$ in the spectrum $(\mathrm{m} / z 615$ to 643 and $m / z 643$ to 671 ). The location of the keto group may be identified by the presence of a radical ion $(\mathrm{m} / z 616$ in Fig. 5c) caused by the homolytic cleavage of the carbonyl/alkyl carbon bond on the proximal side of the ketomeromycolic acid. However, the radical ion does not normally give a strong signal, and derivatization of the keto group to hydroxyl may be necessary to detect possibly co-existing minor homologues, which have a keto group in different locations. 

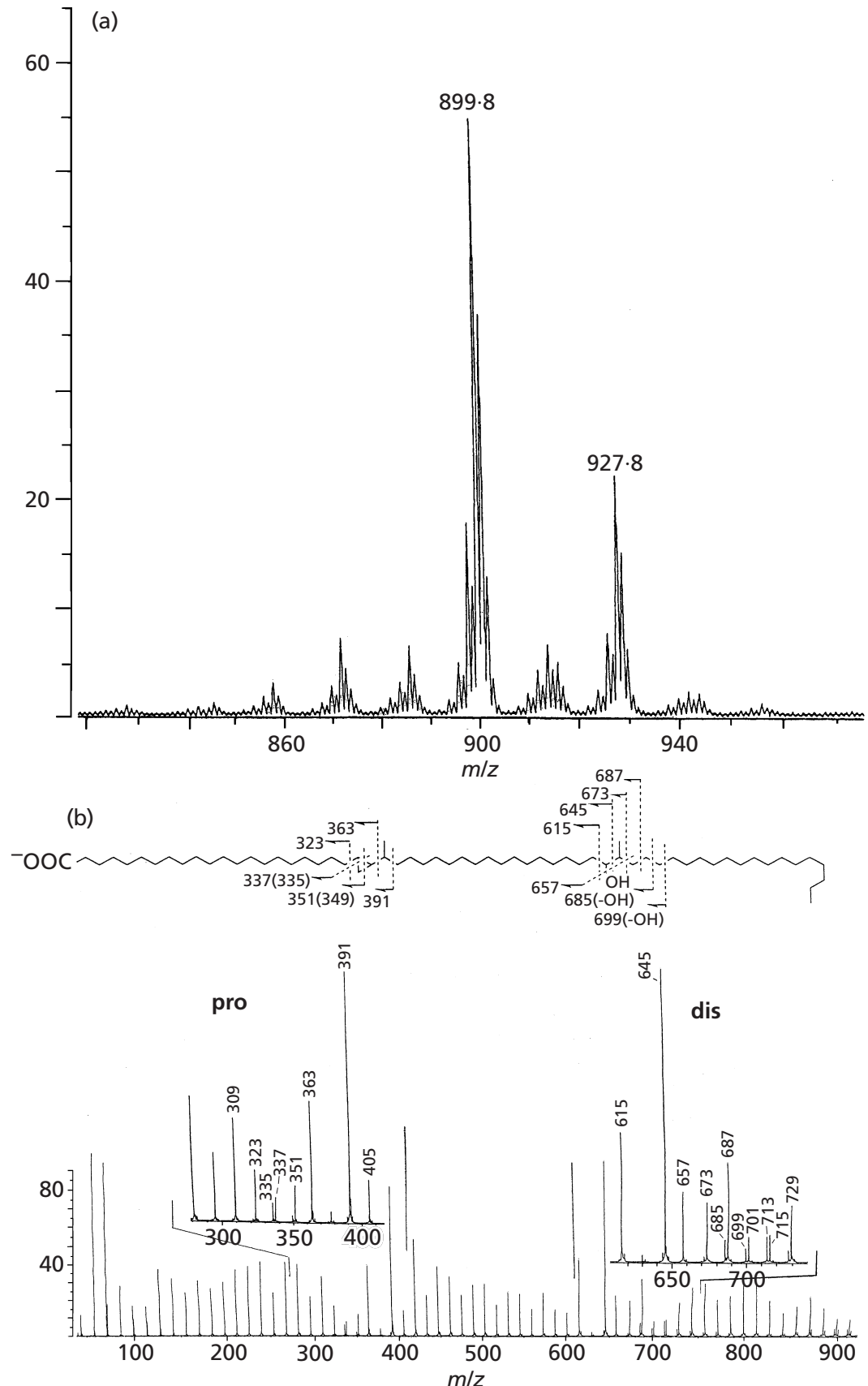

(c)

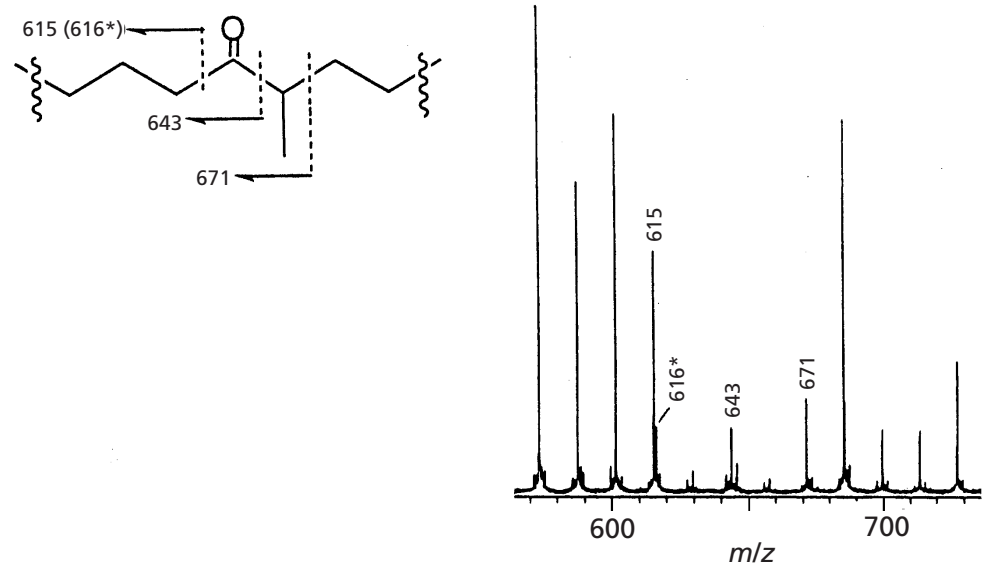

Fig. 5. (a) FAB mass spectrum of hydroxymeromycolic acid derived from type 1 ketomeromycolic acid of MAC KK41-24. (b) CID spectrum of one of the major peaks [927 $\left.(M-\mathrm{H})^{-} ; n-m-l=20-16-17\right)$ from (a), with magnification of the areas involving cleavage of the functional groups and an illustration of the mode of bond cleavage. pro, Proximal vicinity of the trans cyclopropane ring; dis, distal vicinity of the hydroxyl group. (c) Part of the CID spectrum of the corresponding component [925 $\left.(\mathrm{M}-\mathrm{H})^{-}\right]$ of ketomeromycolic acid, from which the hydroxymeromycolic acid analysed in Figs 5(a) and 5(b) was prepared. The spectrum shows the CID-fragmentation profile involving the keto group. 


\section{General structures of meromycolic acids}

The structures of the meromycolic acids determined from the above CID mass spectral analyses are shown in Fig. 1 (I-XIII). In type $3 \alpha$-meromycolic acids from $M$. bovis BCG and Mycobacterium microti the cis double bond is on the distal side (IV), whereas in those from the other M. tuberculosis complex strains, including $M$. tuberculosis $\mathrm{H} 37 \mathrm{Ra}$, the MAC and M. marinum, it is on the proximal side $(\mathrm{V})$.

The methyl branch adjacent to a trans cyclopropane ring was on the distal side, as has been previously indicated by EI/MS in the ketomycolate from $M$. tuberculosis (Minnikin \& Polgar, 1967a). The methyl branch adjacent to a methoxy group was shown to be on the distal side, as recently reported by Schroeder \& Barry (2001) in a study involving ${ }^{13} \mathrm{C}$-labelling. The methyl group adjacent to a keto group was also on the distal side of these groups. In type 2 meromycolic acids with a trans double bond (III, VIII and XII), the adjacent methyl branch was on the proximal carbon, as in the dialkene $\alpha$-mycolate from M. smegmatis (Danielson \& Gray, 1982).

Structures of meromycolic acids with three groups, i.e. type $3 \alpha$-meromycolic $\left(\mathrm{V}^{\prime}\right)$ and type 1 and type 3 methoxymeromycolic ( $\mathrm{VI}^{\prime}$ and $\mathrm{IX}^{\prime \prime}$, respectively) and ketomeromycolic acids ( $\mathrm{X}^{\prime}$ and XIII", respectively) from M. tuberculosis H37Ra, type 3 methoxymeromycolic acids from M. bovis BCG and M. microti (IX'), and type 3 ketomeromycolic acid from M. bovis BCG (XIII'), are shown in Fig. 1. In all of these meromycolic acids, the third group was a cis cyclopropane ring. In the threegroup-containing type 3 methoxy- and keto-meromycolic acids from $M$. bovis BCG and M. microti (IX' and $\left.\mathrm{XIII}^{\prime}\right)$, the cis double bond was near the carboxyl end with a cis cyclopropane ring in the middle. In type $3 \alpha-$ meromycolic, methoxymeromycolic and ketomeromycolic acids from M. tuberculosis H37Ra with a threegroup ( $\mathrm{V}^{\prime}$, IX" and XIII"), the cis double bond was assigned to be mostly in the middle. However, for these acids the CID spectra were generally more complex than those for other components, and the possibility of the presence of the double bond near the carboxyl end cannot be ruled out.

\section{Spacing of functional groups}

The chain lengths between the functional groups, i.e. the $n-m-l$ and $n-n^{\prime}-m-l$ values for $\alpha$-meromycolic, methoxymeromycolic and ketomeromycolic acids as determined by the CID spectral analyses, are summarized in Tables 1, 2 and 3, respectively. Most of the meromycolic acids from the same species were the same in their $n-m-l$ values, although the samples from the $\mathrm{H} 37 \mathrm{Ra}$ strain gave results quite diverse from those of other members of the M. tuberculosis complex, and some of the meromycolic acids from the Canetti strain had a longer $n$ chain than usual. No structural diversity was noted among the samples from various M. bovis BCG strains or from the Tokyo strain cells cultured by different techniques over different growth periods.
Often, two or more homologues with different $n-m-l$ values were present for one $m / z$ component. This made the spectra look more complex and the assignment of the locations of functional groups less feasible. In such cases, the major locations of the groups were judged by choosing fragment ions characteristic of the groups and comparing the intensities of these fragment ions. In Tables 1, 2 and 3 , the $n-m-l$ values of the major homologues for each $m / z$ are given in italics. The characteristic ions used for approximate quantification of methoxy and hydroxy groups were the fragment ions caused by 1,4-elimination of methanol (e.g. the one at $m / z 587$ in the distal spectra of Fig. $4 \mathrm{~b}$ ) and by 1,4elimination of $\mathrm{H}_{2} \mathrm{O}$ (e.g. the one at $m / z 657$ in the distal spectra of Fig. 5 b), respectively. For the double bonds, the radical ions were used as the characteristic ions. In a component containing two or more homologues with their cyclopropane rings in different locations, it was often difficult to determine the precise structures of the major components. In such cases, all possible $n-m-l$ combinations are given in Tables 1, 2 and 3; however, the $n-m-l$ values in these tables do not exclude the possibility of the presence of minor components with other combinations.

Tables 1-3 show that each meromycolic acid consists of one or two, or in some cases more, homologue series with different $m-l$ values. Generally, for each $n-m-l$ series the $n$ value increases as the $m / z$ increases, and after several steps the $m-l$ may be replaced by another series. In all of these $n-m-l$ series, $m$ and $l$ are always the more conservative parts. For example, in type 1 methoxymeromycolic acid from $M$. tuberculosis Canetti with a cis cyclopropane ring, the $n-m-l$ is $17-16-17$ for $m / z$ 871, 19-16-17 for $m / z$ 899, 21-16-17 with some 19-18-17 for $m / z 927$, and mostly 21-18-17 for $m / z$ 955. In some cases, as in the type $3 \alpha$-meromycolic and ketomeromycolic acids from $M$. tuberculosis, single $m$-l series, 14-19 and 18-17, respectively, cover the whole range of $m / z$ for the major components, with $n$ varying from 9 to 17 in the former and from 8 to 19 in the latter.

Meromycolic acids of different $m / z$ values, of different classes or from different origins may have different $m-l$ systems. The $m$ and $l$ values always vary by $28 \mathrm{mu}$ (i.e. two methylene units), as expected for the usual biosynthetic chain-elongation process, whereas $n$ appears to vary by one methylene unit to give a series of ions with 14 mu difference each in the FAB mass spectra.

When the $\mathrm{FAB}$ mass spectrum showed a larger number of ions of similar intensities, the CID spectra of the smaller $\mathrm{m} / \mathrm{z}$ of the series tended to be more complex. This may be due either to inevitable contamination by the fragments from larger $m / z$ components or to the intrinsically more complex $n-m-l$ systems of the smaller $m / z$ components.

The CID spectra showed that the $n-m-l$ series of the meromycolic acids from $M$. tuberculosis H37Ra were more complex, implying the presence of more homologues. The meromycolic acids from this strain were further characterized by shorter $l$ and longer $n$ chains 
compared to those from other M. tuberculosis stains, as shown in Tables 1-3.

\section{DISCUSSION}

Previously, the chain lengths of mycolic acids and the locations of functional groups within them were determined by EI/MS studies of chemically derivatized components. In particular, the positions of the cyclopropane rings within mycolates were established (Minnikin \& Polgar, 1967a, b; Gensler \& Marshall, 1977). However, EI/MS studies on non-derivatized homologous mixtures of mycolic acids do not give reliable information on the location of double bonds, cyclopropane rings and methyl branches within these acids.
In the present study, a series of meromycolic acids were prepared from individual mycolate components and subjected to CID MS. Since meromycolic acid possesses a stable charge site, i.e. a carboxylate anion at one end of the chain, CID MS, in which bond cleavage occurs independently of the charge, provides reliable information about the locations of functional groups, i.e. cis and trans double bonds, cis and trans cyclopropane rings, methoxy and keto groups, and methyl branches.

The precise locations of the functional groups in meromycolic acids, here referred to as the $n-m-l$ and $n$ $n^{\prime}-m-l$ values, were determined by CID MS, and the results of these analyses are shown in Tables $1-3$. On the basis of these $n-m-l$ values, mycolic acid structures were elucidated and are shown in Fig. 6. These pieces of

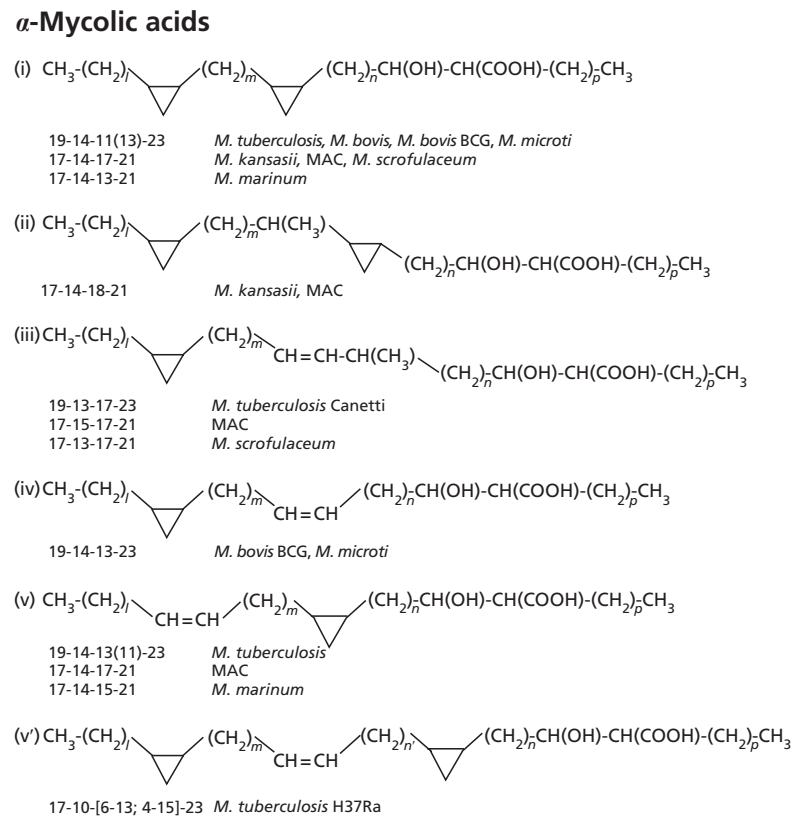

\section{Methoxymycolic acids}

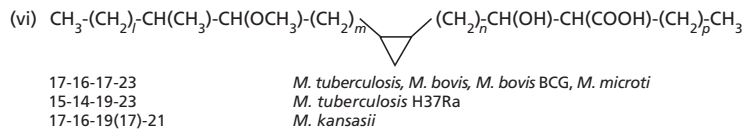

(vii) $\mathrm{CH}_{3}-\left(\mathrm{CH}_{2}\right)-\mathrm{CH}\left(\mathrm{CH}_{3}\right)-\mathrm{CH}\left(\mathrm{OCH}_{3}\right)-\left(\mathrm{CH}_{2}\right)-\mathrm{CH}\left(\mathrm{CH}_{3}\right)$

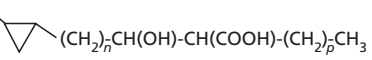

[15-12; 17-10]-6-15-23; [15-12; 17-10]-6-17-23 M. tuberculosis H37Ra

\section{Ketomycolic acids}

(x) $\mathrm{CH}_{3}-\left(\mathrm{CH}_{2}\right)-\mathrm{CH}\left(\mathrm{CH}_{3}\right)-\mathrm{CO}-\left(\mathrm{CH}_{2}\right)$

$17-18-15-23$
$15-16-19-23$

$15-20-17-21$

$15-18-17-21$

(xi) $\mathrm{CH}_{3}-\left(\mathrm{CH}_{2}\right)-\mathrm{CH}\left(\mathrm{CH}_{3}\right)-\mathrm{CO}-\left(\mathrm{CH}_{2}\right)-\mathrm{m}\left(\mathrm{CH}\left(\mathrm{CH}_{3}\right)\right.$

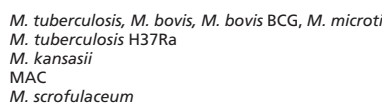

\section{$17-18-16-23$}

$15-18-18-23$

$15-16-18-2$

M. tuberculosis, M. bovis, M. bovis BCG, M. microt

M. kansa

M. scrofulaceum

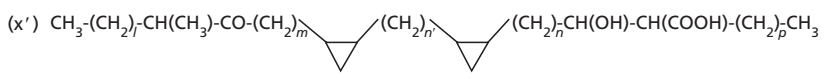

[15-10; 17-8]-[12-13; 10-15; 8-17]-23; [15-12; 17-10]-[10-13; 8-15; 6-17]-23 M. tuberculosis H37Ra

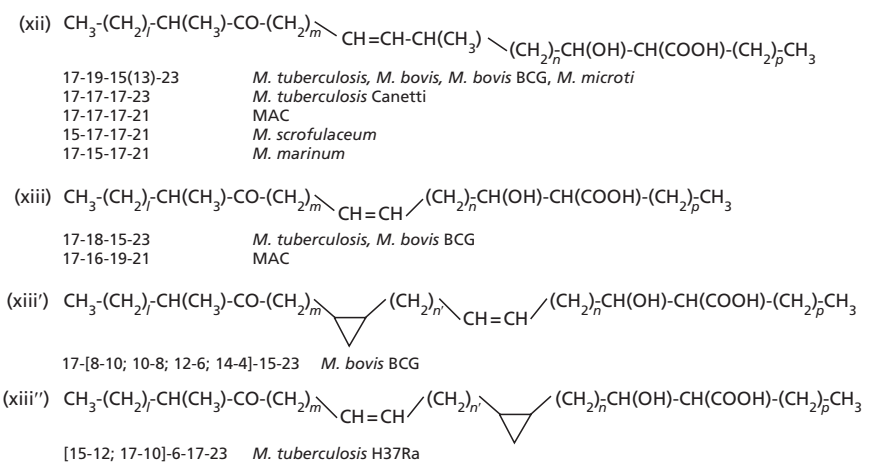

[15-12; 17-10]-6-17-23 M. tuberculosis H37Ra

Fig. 6. Structures and distribution of defined mycolic acids. Main component values are expressed as $I-m-n-p$ or $I-m-n^{\prime}-n-$ $p$. Values in parentheses indicate an additional major component, which may be the main one in some samples. All possible figure combinations are given in square brackets, in cases where it was hard to decide which was the major one. M. tuberculosis does not include M. tuberculosis H37Ra. In (iii), (vii), (viii) and (xii), M. tuberculosis Canetti is not included. The structures are numbered to correspond to the types of meromycolic acids shown in Tables 1-3 and in Fig. 1. 
information on the precise structure of mycolic acids may provide more definite insights into the biosynthetic relationships between various types and classes of meromycolic acids from various mycobacteria. This information may also shed light on the physiological features of the cell-wall mycolate layer in mycobacteria, as the compactness of the mycolate layer should be directly related to the structure of or locations of functional groups in the component mycolates.

Relationship between type 1 and type 3 meromycolic acids. Mass distribution and $n-m-l$ values suggested a close relationship between the type 1 meromycolic acids with a cis cyclopropane ring and the corresponding type 3 meromycolic acids. The type $1 \alpha$-meromycolic acids with a cis cyclopropane ring from the M. tuberculosis complex, the MAC and M. marinum (I, Table 1) had corresponding type $3 \alpha$-meromycolic acids with the same $n$ - $m$ - $l$ values as the type $1 \alpha$-meromycolic acids, but with molecular masses 14 mu lower (IV and V, Table 1). What is more, the $m / z$ of the most abundant component of type 1 (I) was always higher than that of the corresponding most abundant component of type 3 (IV) or type $3(\mathrm{~V})$ by $14 \mathrm{mu}$.

The relationship between the cis-cyclopropane-containing type 1 and type 3 components was also generally observed in ketomeromycolic acids when both types were analysed, i.e. those from the M. tuberculosis complex and the MAC (X and XIII, Table 3). In methoxymeromycolic acids from the $M$. tuberculosis complex (Table 2 ), the $m$ - $l$ value of the major type 1 meromycolic acids (VI) was $16-17$ or $18-17$, whereas that of the major type 3 component (IX) was 18-17. The same relationship between the type 1 and type 3 meromycolic acids was also noted between the meromycolic acids with three groups (Table 1). In the methoxymeromycolic acids from $M$. tuberculosis $\mathrm{H} 37 \mathrm{R}$ a, the $m / z$ of the most abundant of the type 3 components (IX"), all with three groups with $m / z 869$ and $n-n^{\prime}-m-l$ values of $15-6-10-17$ and 15-6-12-15, had the corresponding type 1 components $\left(\mathrm{VI}^{\prime}\right)$, having $m / z 883$ and the same $n-n^{\prime}-m-l$ values. The same relationship was noted between the type 1 and type 3 ketomeromycolic acids with three groups from the same strain ( $\mathrm{X}^{\prime}$ and XIII").

The FAB mass spectra of type 1 meromycolic acids normally gave only two or three major ions (Fig. 5a), whereas those of type 3 meromycolic acids often gave a series of ions with a wider range of $m / z(n)$ values. Perhaps the enzyme systems involved in the derivatization of type 3 components into type 1 components work only on certain type 3 components of appropriate $n$-chain lengths, with the rest being left as type 3 meromycolic acids?

Although type 1 methoxy- and keto-meromycolic acids with two groups (VI and X, respectively) from $M$. tuberculosis $\mathrm{H} 37 \mathrm{R}$ a do not seem to have corresponding type 3 components with two groups, the observations described above apparently support the biosynthetic postulate that a cis double bond in meromycolic acids is a direct substrate for cis cyclopropanation.
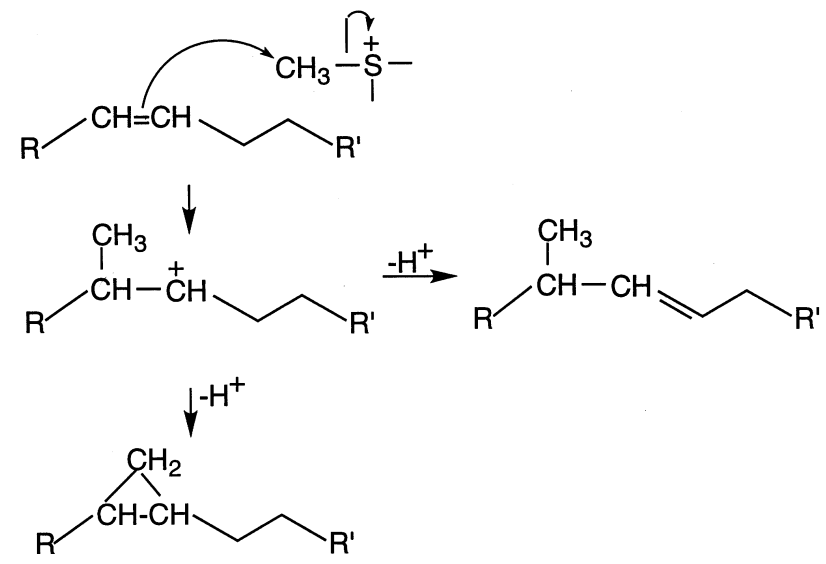

Fig. 7. Lederer's scheme showing the possible relationship between a cis double bond, a cis cyclopropane ring and a trans double bond with an adjacent methyl branch in meromycolic acid (Lederer, 1969).

Relationship between cis- and trans-cyclopropane-containing components. Type $1 \alpha$-meromycolic acids from $M$. kansasii and the MAC, and type 1 methoxy- and ketomeromycolic acids from all of the strains tested, except those from M. tuberculosis H37Ra, consisted of both cis- and trans-cyclopropane-containing components. In these type 1 meromycolic acids, almost any component with a trans cyclopropane with ' $n-m-l$ ' had a corresponding type 1 component with a cis cyclopropane whose $m / z$ was $14 \mathrm{mu}$ less, with ' $(n+1)-m-l$ '. For example, type $1 \alpha$-meromycolic acid with a trans cyclopropane ring (II) from $M$. kansasii $m / z$ 853, whose $n-m-l$ values were $18-14-17$ and $18-12-19$, had the corresponding component with a cis cyclopropane (I) of $m / z 839$, whose $n$ - $m$ - $l$ values were $19-14-17$ and 19-1219. The structural relationships between the cis-doublebond-containing, cis-cyclopropane-containing and trans-cyclopropane-containing meromycolic acids having $n-m-l, n-m-l$ and $(n-1)-m-l$, respectively, may be explained by the scheme proposed by Lederer (1969) (Fig. 7). This scheme involves the introduction of a methionine methyl across a cis double bond in the meromycolic acid chain, which may then form a cis cyclopropane. Alternatively, it can form a trans double bond with an allylic methyl group on the distal side when $\mathrm{R}^{\prime}$ in Fig. 7 is the carboxyl end, which may be then cyclopropanated to a trans cyclopropane ring with an adjacent methyl group on the distal carbon. This explains the formation of a trans cyclopropane ring in the original type 3 meromycolic acid with a cis double bond without a change in the $m$-chain length, but with an increase in the molecular mass of $28 \mathrm{mu}$. Cyclopropanation of a trans double bond in the meromycolate chain has been suggested (Yuan et al., 1998; Barry et al., 1998), and many of the enzyme systems involved in the scheme have been identified (Barry et. al, 1998).

Pairs of cis-cyclopropane-containing and trans-cyclopropane-containing meromycolic acids, showing the relationships described above, were observed commonly 
in the type 1 meromycolic acids where the two relevant $n-m-l$ series were present. However, the molecular mass distribution of the two series matched only in type 1 methoxymeromycolic acids from M. kansasii and ketomeromycolic acids from the M. tuberculosis complex, M. kansasii, the MAC and M. scrofulaceum. In $\alpha$ meromycolic acids from M. kansasii and the MAC, and methoxymeromycolic acids from M. tuberculosis Canetti, the molecular mass difference between the most abundant components of the two series was $42 \mathrm{mu}$ or more. The molecular mass difference between the pairs of components of the type 1 methoxymeromycolic acids from M. tuberculosis Canetti [(VI, $m / z$ 871, 17-16-17) and (VII, $m / z$ 969, 22-16-17)] was $98 \mathrm{mu}$, or 7 methylene units.

The mass difference between the most abundant of the two series was due to the larger $n$ values in the transcyclopropane-containing components, as both series had the same $m-l$ system. It is possible that elongation in $n$ may take place after the introduction of the trans cyclopropane ring into the chain, or that the transcyclopropanation enzyme system prefers type 3 meromycolates with longer $n$ chains as its substrate.

Relationship between type $\mathbf{2}$ meromycolic acids and other meromycolic acids. In some $\alpha$-meromycolic acids, type 1 and type 2 components with the same $m / z$ display an $n-m-l$ and $n-(m-1)-l$ relationship. For example, in $\alpha$-meromycolic acids from $M$. scrofulaceum, the most abundant type 1 component of $\mathrm{m} / z \quad 811$ and the most abundant type 2 component of $m / z 811$ was 17-14-17 and 17-13-17, respectively.

In $\alpha$-meromycolic acids from $M$. tuberculosis Canetti, type $2 \alpha$-meromycolic acids with $n$ - $(m-1)-l$ correspond to type 1 components with $n-m-l$. However, the mass of the most abundant of the type 2 component was 839 ( $n$ $m-l$ 17-13-19), whereas that of the corresponding most abundant type 1 component was 755 ( $n$-m-l 11-14-19), producing $84 \mathrm{mu}$ (6 methylene units) difference in the $m / z$ between the two. The corresponding type $3 \alpha-$ meromycolic acid of $n-m-l 17-14-19(m / z 825)$ was only a minor component. This raises the possibility that type 2 components may not be directly derived from a type 3 component.

The $n-m-l$ relationships outlined in the cases above suggest that the relationship between the type 1 and type 2 meromycolic acids is similar to that between the ciscyclopropane-containing components and the transcyclopropane-containing components of type 1 meromycolic acids. According to Lederer's scheme (1969; Fig. 7), the methyl group may be introduced to either carbon of the cis double bond to form a trans double bond with a methyl group on either the proximal or the distal carbon of the double bond. Thus, when $\mathrm{R}$ is the carboxyl-containing end in Fig. 7, the type 2 meromycolic acids presented here, containing a trans double bond with a methyl on the proximal carbon, may be produced. Only those trans double bonds with a methyl on the distal side may serve as a direct substrate for trans cyclopropanation to form type 1 meromycolic acids with a trans cyclopropane, whereas those with a methyl on the proximal carbon (i.e. the type 2 meromycolic acids presented here) may remain as type 2 meromycolate. Glickman et al. (2001) reported that CmaA2, an enzyme involved in trans cyclopropanation, did not produce a trans cyclopropane in trans-double-bondcontaining mycolate-producing M. smegmatis.

In methoxy- and keto-meromycolic acids from the $M$. tuberculosis complex and the MAC, the more generally observed rule between the type 1 and type 2 components is that the type 1 meromycolic acids with a cis cyclopropane (VI and X) have $n-m$ - $l$, whereas the type 2 components (VIII and XII) have $(n-2)-(m+1)-l$. This relationship applies to the majority of the type 1 and the corresponding type 2 components of these two classes. What is more, in these classes, the $m / z$ values of the most abundant of the type 1 components (VI, X) and those of the corresponding type 2 components (VIII, XII) are mostly the same. However, the biosynthetic relationship between the type 2 meromycolic acids and the corresponding type 1 components, or some other components, is not defined.

Thus, an apparently different type 1 /type 2 structural relationship is observed between the $\alpha$-meromycolic acids and the oxygenated meromycolic acids, which may suggest that these two groups of mycolates have their own different biosynthetic systems.

Relationship between meromycolic acids with two groups and those with three groups. Type $3 \alpha$-meromycolic acids and type 1 methoxy- and keto-meromycolic acids from M. tuberculosis $\mathrm{H} 37 \mathrm{Ra}$, type 3 methoxymeromycolic acids from $M$. bovis BCG and M. microti, and ketomeromycolic acid from $M$. bovis BCG consist of components with two functional groups and components with three functional groups $\left(\mathrm{V}-\mathrm{V}^{\prime}, \mathrm{VI}-\mathrm{VI}^{\prime}, \mathrm{X}-\mathrm{X}^{\prime}\right.$, IX-IX' and XIII-XIII', respectively). In each case, the $m / z$ value of the most abundant of the three-groupcontaining series was $40 \mathrm{mu}$ higher than that of the corresponding two-group-containing components, implying the introduction of a cyclopropane ring into the two-group-containing component.

The type 3 methoxymeromycolic acids with three functional groups from M. bovis BCG and M. microti, and the type 3 ketomeromycolic acid with three groups from $M$. bovis BCG, all with $n-n^{\prime}-m-l$, were related to the corresponding components with two functional groups from the same strains $\left[n-\left(n^{\prime}+m\right)-l\right]$. It may be that unsaturation is introduced into the longer $m$ chains of the meromycolic acids, which may have been produced for some reason, in M. bovis BCG and M. microti cells, to form a new cis double bond in the $m$ chain.

In the case of $M$. tuberculosis H37Ra, the $n-m-l$ values suggested that type 1 methoxy- and keto-meromycolic acids with three groups ( $\mathrm{VI}^{\prime}$ and $\left.\mathrm{X}^{\prime}\right)$ and type 3 methoxyand keto-meromycolic acids (IX" and XIII") from $M$. tuberculosis $\mathrm{H} 37 \mathrm{Ra}$ are structurally more closely related to the corresponding methoxy- and keto-meromycolic acids from other members of the M. tuberculosis 
complex that have two functional groups (VI and X; IX and XIII) than to the corresponding two-group-containing components from H37Ra, though no two-groupcontaining type 3 methoxy- and keto-meromycolic acids were isolated from this strain. For example, a component of $\left(\mathrm{VI}^{\prime}\right) m / z$ 911, whose $n-n^{\prime}-m-l$ is $17-8-8-17$ or 17-6-10-17, is related to the type 1 methoxymeromycolic acid from the M. tuberculosis complex with two groups (VI) of $m / z 871$, whose $m / z$ is $40 \mathrm{mu}$ less and whose $n$ $m-l$ is $17-16-17$. The other component of $\left(\mathrm{VI}^{\prime}\right) m / z 883$, with 15-8-8-17 or 15-6-10-17, is related to the component $m / z 843$ of (VI), whose $n-m-l$ is $15-16-17$, in the same manner. This suggests the introduction of a cis cyclopropane ring into the $m$ chain of the latter. An analogous relationship is observed between (X) and (XIII) from $M$. tuberculosis and $\left(\mathrm{X}^{\prime}\right)$ and $\left(\mathrm{XIII}^{\prime \prime}\right)$, respectively. It may suggest that the cells of this strain may produce, along with its own mycolates, some mycolates of the parent $M$. tuberculosis, and that their $m$ chains may be subjected to the introduction of unsaturation.

Hence, the newly introduced double bond may be ciscyclopropanated, to form the three-group-containing type 3 methoxy- and keto-meromycolic acids from $M$. bovis BCG and M. microtii and the type 1 methoxy- and keto-meromycolic acids from M. tuberculosis H37Ra. In the type 3 methoxy- and keto-meromycolic acids from H37Ra, the original proximal double bond may be cis-cyclopropanated.

Some of the $n-n^{\prime}-m-l$ values of (IX') and (IX") are the same, and so are those of (XIII') and (XIII"). This may support the above-described assumption.

In the case of $\alpha$-meromycolic acids, comparison of the $n$ $m-l$ of a component (V) from M. tuberculosis H37Ra (most abundant, 19-10-17; next, 17-10-17) with the $n-n^{\prime}$ $m-l$ of a component $\left(\mathrm{V}^{\prime}\right)$ whose $m / z$ was $40 \mathrm{mu}$ higher [most abundant, 15-4-(13-6-)10-17; next 13-4-(11-6-)1017], suggested the introduction of a cis cyclopropane ring to the $n$ chain of $(\mathrm{V})$. This may also provide evidence that in the $\alpha$-mycolates, and the oxygenated mycolates, different biosynthetic systems may be working.

Relationship between methoxy- and keto-meromycolic acids. CID spectra are available for the pairs of the type 1 methoxy- and keto-meromycolic acids from $M$. kansasii and for the type 1, type 2 and type 3 methoxyand keto-meromycolic acid pairs from the M. tuberculosis complex. In those pairs analysed, including those of the three-group-containing components from M. tuberculosis H37Ra, the most abundant meromycolic acid components of the two classes had the same $n$ $m-l$ values. The fact that both the molecular mass distributions and the $n-m-l$ relations of the two classes in each pair generally matched may imply the presence of a very immediate common precursor for the two oxygenated meromycolic acids, as suggested previously (Dubnau et al., 1997). One exception was noted, however, in the pairs of type 2 meromycolic acids from M. tuberculosis Canetti; the $n$ - $m$ - $l$ of the most abundant methoxymeromycolic acid was 15-19-17, whereas that of the most abundant ketomeromycolic acid was 17-1717.

Meromycolic acids from $M$. tuberculosis H37Ra. Previously, the mycolates from M. tuberculosis H37Ra, originally derived from M. tuberculosis H37 (Steenken \& Gardner, 1946), were shown to be characterized by an increased three-group-containing mycolate content and a higher cis group or an extremely low trans group content (Watanabe et al., 2001). The presence of ketomycolate with an additional cyclopropane ring has been implied previously by Takayama et al. (1979).

The present CID MS studies showed that the structures $(n-m-l)$ of the meromycolic acids from H37Ra were different from those from other M. tuberculosis strains. They were characterized by more complex $n-m-l$ series, and shorter $l$ and longer $n$ chains. $l$ was 17 for the $\alpha$-meromycolic acid, and 15 and 17 for the methoxyand keto-meromycolic acids; $n$ was mostly 17 and 19 for the $\alpha$-meromycolic acids, and mostly 19 and 21 for the methoxy- and keto-meromycolic acids, with the exception of those components with three functional groups.

Previously, Qureshi et al. (1978) separated the $\alpha$ mycolate from H37Ra into several fractions by HPLC and subjected each fraction to EI/MS. The authors concluded that the major $m$ - $l$ of the mycolates from this strain should be 10-17. According to the present results, the $m-l$ of 10-17 may be present, but it is apparently not the sole major series for the $\alpha$-mycolates from H37Ra.

Structures of meromycolic acids and pathogenicity. Pathogenicity is the result of the combined effect of a number of complex factors. However, one essential factor needed for mycobacteria to be human pathogens is the capacity of the bacterial cells to thrive in human macrophages. Essentially and critically, the mycolate layer of the bacterial cell wall should act as a barrier to both hydrophilic and hydrophobic attack by host macrophages. Different mycolic acids are considered to contribute differently to the mycolate layer and to its structure and function, as implied in papers referred to in the Introduction. Thus, to elucidate the functions and features of the mycolate layer, the structures of its constituent mycolates must be precisely defined. Liu \& Nikaido (1999) have demonstrated the hypersensitivity of mycolate-deficient $M$. smegmatis cells to various hydrophobic antibiotics.

The present study has revealed distinct structural characteristics for the meromycolic acids from strains of the M. tuberculosis complex, with the exception of H37Ra. These meromycolic acids, all similar to each other, are characterized by more regular and steady $m$ - $l$ systems (one $m-l$ covers a wider range of $m / z$ ), and longer $l$ and shorter $n$ chains (Tables 1-3). These characteristic features of the chain lengths are most emphatically and clearly seen in the $\alpha$-meromycolic acids, where $l$ is almost exclusively 19 and $n$ of the most abundant component is 11 or 13 . Since $\alpha$-mycolate constitutes about $50 \%$ of the total cell-wall mycolates 
from M. tuberculosis, its characteristic chain lengths should provide the cell-wall mycolate layer of $M$. tuberculosis with specific physico-chemical features. The definite effects of the chain lengths, or $l, m$ and $n$ values, of the constituent mycolates on the cellwall mycolate layer structure are not known. However, $n-m-l$ values should be at least one critical factor that contributes to the compactness of the mycolate arrangement in the cell-wall mycolate layer and, probably, to its function as a permeability barrier. The importance of the proximal functional groups of the meromycolate chain for the cell wall of the lowest fluidity region of the mycolate layer has been mentioned (Barry et al., 1998). The effect of the proximal functional groups might be more profound if they were located nearer to the base of the cell wall.

Previously, we reported that the mycolates from various M. bovis BCG strains had higher ketomycolate contents, higher three-group-containing mycolate contents and higher cis group contents than those from M. bovis (Watanabe et al., 2001). The present results demonstrated that the differences noted previously are only quantitative ones, and that the structures of individual mycolic acids from $M$. bovis and M. bovis BCG are identical. In the case of M. tuberculosis, the structures or the chain lengths of meromycolic acids from various clinical isolates and those from repeatedly subcultured standard strains, such as the strains Aoyama B and $\mathrm{H} 37 \mathrm{Rv}$, are the same. This observation implies that repeated subculturing may affect the mycolate composition ratios but not their structures. This suggests that M. tuberculosis H37Ra, whose meromycolic acids have $n-m-l$ systems different to those from the $M$. tuberculosis complex, may have been produced by a process involving some genetic rearrangement.

M. tuberculosis and M. bovis, whose mycolates have similar cis/trans ratios and compositions, and whose meromycolic acid structures are the same (and accordingly produce a similar cell-wall mycolate layer), are human pathogens. M. bovis BCG and M. microti, whose meromycolic acids have the same $n-m-l$ system as those from M. tuberculosis but with different mycolate ratios, different cis/trans ratios and different double bond contents, are not considered to be human pathogens. In M. kansasii, another human pathogen whose mycolate composition is generally similar to that of $M$. tuberculosis, the chain structures of the oxygenated meromycolic acids are also analogous to those of the corresponding components from M. tuberculosis; however, the structures of the meromycolic acid chains of its $\alpha$-mycolates, constituting about half of the total mycolates, are different. This difference may account for the observed differences in the sensitivity to antibiotics of these two species and the level of pathogenicity displayed by these two species, and may provide evidence for the relationship between the mycolate chain structures and the nature of the mycolate layer. M. tuberculosis H37Ra, whose $\alpha$-, methoxy- and keto-mycolate ratio is similar to that of the M. tuberculosis complex but whose meromycolic acid structures are quite different from those of the M. tuberculosis complex, is not considered to be pathogenic. Thus, if the cell-wall mycolate layer or its function as a permeability barrier is the key to the pathogenicity of $M$. tuberculosis, both the mycolate compositions and the mycolate chain structures are the key factors which decide its pathogenicity.

The present structural studies also revealed a marked similarity between the meromycolic acids from M. bovis BCG and M. microti, both considered not to be human pathogens and known to have similar mycolate compositions (Watanabe et al., 2001). In addition to the same $n$ - $m$-l systems, the type $3 \alpha$-meromycolic acids from these two species have the cis double bond in the distal position.

Biosynthesis of meromycolates. A couple of review articles describe the currently accepted biosynthetic pathways for the mycobacterial mycolic acids (Brennan \& Nikaido, 1995; Barry et al., 1998). Not all of the steps involved in the biosynthetic process have been experimentally verified as yet, but it must be that the meromycolates are synthesized first, and then go through a Claisen-type condensation to produce the mycolates. Liu \& Nikaido (1999) isolated a mutant $M$. smegmatis strain that does not synthesize proper mycolates but which accumulates defective meromycolates, which are bound to the arabinogalactan structure (Wang et al., 2000). The accumulated defective meromycolates, having two cis double bonds and the $l$ - and $m$-chain lengths of the proper M. smegmatis $\alpha$-mycolates, possess a range of much shorter $n$ chains. Currently, it is not known what other biological systems are defective in this mutant strain, but the results of Liu \& Nikaido (1999) seem to agree with our present observations and assumptions.

It has not yet been definitely demonstrated at which stage of meromycolate synthesis the functional groups are introduced (Barry et al., 1998), but in the accumulated meromycolates of the defective $M$. smegmatis strain, the two cis double bonds are in the right position, even though $n$-chain formation is not complete. Along with our present observation that in all meromycolic acids $m-l$ is the more steady part, this information suggests that $n$-chain elongation occurs after the locations of the major functional groups have been allotted to the right place in the meromycolic acid chain. Unsaturation occurs during elongation of the chain, not after the completion of the full-length meromycolate chain.

The two double bonds in the accumulated meromycolates with shorter $n$ chains are both cis. No trans double bond is detected, which is the functional group in another major component of the M. smegmatis mycolates. It is likely that meromycolates with cis double bonds are first produced, which have a range of proper $n$-chain lengths (as in Tables 1-3). Then those meromycolic acids with certain $n$-chain lengths, having an acyl-carrier protein at the carboxyl end, may serve as specific substrates for certain enzyme systems involved in the derivatization of the cis double bond. This 
explains why no trans group was detected in the defective M. smegmatis meromycolates, as the $n$ chains may have possibly been too short for the enzymes, and why normally only two or three major component ions are seen in the FAB mass spectra of type 1 meromycolic acids (Fig. 5a), when a larger number of ions are present in the FAB mass spectra of type 3 meromycolic acids. It may also explain why the most abundant major components of cis-cyclopropane-containing and trans-cyclopropane-containing type 1 meromycolic acids often have different $n$-chain lengths.

The differences in molecular mass distribution or in the $n$-chain lengths between the meromycolic acids of two different types, apparently derived from the same precursor, may be ascribed to the preference of the specific enzymes involved in mycolate-layer biosynthesis for the substrate or for the specific $n$-chain lengths. However, the $n$-chain lengths of the type $2 \alpha$-meromycolic and trans-cyclopropane-containing type 1 methoxymeromycolic acids from $M$. tuberculosis Canetti (most abundant components having $n-m-l$ 17-13-19 and 22-16-17, respectively) are much longer than expected. The $n-m-l$ value of the most abundant of the possible type 3 precursors for the former is 11(13)-14-19 and that of the most abundant of the related cis-cyclopropanecontaining components is 17-16-17. In both cases, the corresponding components having the $n$-chain lengths of the trans components are minor ones. Although no relevant enzyme systems are known, this information suggests that $n$-chain elongation of those derivatized meromycolates still retaining an acyl-carrier protein at their carboxyl end may be considered possible.

Previously, it has been shown that $\alpha$-mycolates and oxygenated mycolates have different total chain lengths, and that although the mycolate ratios vary among strains of $M$. tuberculosis, or among cultures of $M$. bovis BCG Tokyo and M. microti grown under different culture conditions or for different periods of time, the ratios between the $\alpha$-meromycolate concentration and the methoxy- plus keto-mycolate concentration remain constant (Watanabe et al., 2001). Therefore, if these two groups of mycolates are to be derived from a common precursor, they must be derived at an early stage of biosynthesis (Brennan \& Nikaido, 1995). The abovedescribed defective M. smegmatis meromycolates and our present results support this theory. The defective $M$. smegmatis meromycolate had the $m-l$ values of the proper meromycolates before proper $n$-chain formation. If an analogous process proceeds in M. tuberculosis, $M$. tuberculosis cells may produce meromycolates with an $m$ - $l$ of 14-19 for $\alpha$-meromycolates and an $m-l$ of 18-17 for the oxygenated meromycolates. Thus, if $\alpha$-mycolates and oxygenated mycolates are to share the same precursor, they must share it in the initial stage of the biosynthesis of meromycolates.

Our present results may add further evidence that the synthesis of $\alpha$-mycolates and oxygenated mycolates involves some different or independent enzyme systems. In $\alpha$-meromycolic acids, when type 1 meromycolic acids have the $n-m$ - $l$ structure the type 2 components have $n$ $(m-1)-l$, whereas in the oxygenated meromycolic acids, when type 1 components have $n-m-l$ the system for the type 2 components is $(n-2)-(m+1)-l$. When a third group is introduced into the components with two groups, in the $\alpha$-meromycolic acids it is introduced into the $n$ chain and in the oxygenated meromycolic acids it is introduced into the $m$ chain. However, only one $\alpha$ meromycolic acid with three groups was analysed in the present study.

In the present study, analyses were made on only a limited number of meromycolic acids. Comparison of the $n-m-l$ values of a larger number of meromycolic acids from more mycobacteria may reveal more definite biosynthetic relationships between various mycolic acid chains.

\section{ACKNOWLEDGEMENTS}

D.E.M. was funded by Medical Research Council Cooperative (49343) and Project (49338) grants; M.R. was supported by the Oscar II Jubilee Fund of the Swedish Heart and Lung Foundation.

\section{REFERENCES}

Adams, J. \& Songer, M. J. (1993). Charge-remote fragmentations for structural determination of lipids. Trends Anal Chem 12, 28-35.

Barry III, C. E., Lee, R. E., Mdluli, K., Sampson, A. E., Schroeder, B. G. \& Slayden, R. A. (1998). Mycolic acids: structure, biosynthesis and physiological functions. Prog Lipid Res 37, 143-179.

Brennan, P. J. \& Nikaido, H. (1995). The envelope of mycobacteria. Annu Rev Biochem 64, 29-63.

Chen, C. \& Gross, M. L. (2000). Applications and mechanism of charge-remote fragmentation. Mass Spectrom Rev 19, 398-420.

Cordero, N. \& Wesdemiotis, C. (1994). Characterization of the neutral products formed upon the charge-remote fragmentation of fatty acid ions. Anal Chem 66, 861-866.

Crockett, J. S., Gross, M. L., Christie, W. W. \& Holman, R. T. (1990). Collision activation of a series of homoconjugated octadecadienoic acids with fast atom bombardment and tandem mass spectrometry. Am Soc Mass Spectrom 1, 183-191.

Danielson, S. J. \& Gray, G. R. (1982). Structures of the two homologous series of dialkene mycolic acids from Mycobacterium smegmatis. J Biol Chem 257, 12196-12203.

Dmitriev, B. A., Ehlers, S., Rietschel, E. T. \& Brennan, P. J. (2000). Molecular mechanics of the mycobacterial cell wall: from horizontal layers to vertical scaffolds. Int J Med Microbiol 290, 251-258.

Draper, P. (1998). The outer parts of the mycobacterial envelope as permeability barriers. Front Biosci 3, 1253-1261.

Dubnau, E., Lanéelle, M. A., Soares, S., Benichou, A., Vaz, T., Prome, D., Promé, J. C., Daffé, M. \& Quémard, A. (1997). Mycobacterium bovis BCG genes involved in the biosynthesis of cyclopropyl keto- and hydroxy-mycolic acids. Mol Microbiol 23, 313-322.

Dubnau, E., Chan, J., Raynoud, C., Mohan, V. P., Lanéelle, M. A., Yu, K., Quémard, A., Smith, I. \& Daffé, M. (2000). Oxygenated mycolic acids are necessary for virulence of Mycobacterium tuberculosis in mice. Mol Microbiol 36, 630-637. 
Gensler, W. J. \& Marshall, J. P. (1977). Structure of mycobacterial bis-cyclopropane mycolates by mass spectometry. Chem Phys Lipids 19, 128-143.

George, K. M., Yuan, Y., Sherman, D. R. \& Barry III, C. E. (1995). The biosynthesis of cyclopropanated mycolic acids in Mycobacterium tuberculosis. J Biol Chem 270, 27292-27298.

Glickman, M. S., Cahill, S. M. \& Jacobs, W. R., Jr (2001). The Mycobacterium tuberculosis cmaA2 gene encodes a mycolic acid trans-cyclopropane synthetase. J Biol Chem 276, 2228-2233.

Jackson, M., Raynaud, C., Lanéelle, M. A., Guilhot, C., LaurentWinter, C., Ensergulix, D., Gicquel, B. \& Daffé, M. (1999). Inactivation of the antigen $85 \mathrm{C}$ gene profoundly affects the mycolate content and alters the permeability of the Mycobacterium tuberculosis cell envelope. Mol Microbiol 31, 1573-1587.

Jensen, N. J., Tomer, K. B., Gross, M. L. \& Wesdemiotis, C. (1985). Gas-phase ion decompositions occurring remote to charge site. J Am Chem Soc 107, 1863-1868.

Krembel, J. \& Etémadi, A. H. (1966). Sur la structure d'un nouveau type d'acides mycoliques de Mycobacterium smegmatis. Tetrabedron 22, 1113-1119.

Lederer, E. (1969). Some problems concerning biological Calkylation reaction and phytosterol biosynthesis. Q Rev Chem Soc Lond 23, 453-481.

Liu, J. \& Nikaido, H. (1999). A mutant of Mycobacterium smegmatis defective in the biosynthesis of mycolic acids accumulates meromycolates. Proc Natl Acad Sci U S A 96, 4011-4016.

Liu, J., Barry III, C. E., Besra, G. S. \& Nikaido, H. (1996). Mycolic acid structure determines the fluidity of the mycobacterial cell wall. J Biol Chem 271, 29545-29551.

McNeil, M., Daffé, M. \& Brennan, P. J. (1991). Locations of the mycoloyl ester substituents in the cell walls of mycobacteria. J Biol Chem 266, 13217-13223.

Minnikin, D. E. \& Polgar, N. (1967a). The methoxymycolic and ketomycolic acids from human tubercle bacilli. Chem Commun (J Chem Soc Sect D) 1172-1174.

Minnikin, D. E. \& Polgar, N. (1967b). The mycolic acids from human and avian bacilli. Chem Commun (J Chem Soc Sect D) 916-918.

Paul, T. R. \& Beveridge, J. (1992). Re-evaluation of envelope profiles and cytoplasmic ultrastructure of mycobacteria processed by conventional embedding and freeze-substitution protocols. J Bacteriol 174, 6508-6517.
Paul, T. R. \& Beveridge, J. (1994). Preservation of surface lipids and determination of ultrastructure of Mycobacterium kansasii by freeze-substitution. Infect Immun 62, 1542-1555.

Qureshi, N., Takayama, K., Jordi, H. C. \& Schnoes, H. K. (1978). Characterization of the purified components of a new homologous series of alpha-mycolic acids from Mycobacterium tuberculosis H37Ra. J Biol Chem 253, 5411-5417.

Savagnac, A., Aurella, H., Casas, C., Couderc, F., Gavard, P., Promé, D. \& Promé, J. (1989). Structure determination of mycolic acids by using charge-remote fragmentation. Chem Phys Lipids 51, 31-38.

Schroeder, B. G. \& Barry III, C. E. (2001). The specificity of methyl transferases involved in trans mycolic acid biosynthesis in Mycobacterium tuberculosis and Mycobacterium smegmatis. Bioorg Chem 29, 164-177.

Steenken, W., Jr \& Gardner, L. U. (1946). History of H37 strain of human tubercle bacillus. Am Rev Tuber 54, 62-66.

Takayama, K., Qureshi, N., Jordi, H. C. \& Schnoes, H. K. (1979). Separation of homologous series of mycolic acids from Mycobacterium tuberculosis $\mathrm{H} 37 \mathrm{R}$ a by high performance liquid chromatography. In Biological/Biochemical Applications of Liquid Chromatography, pp. 91-101. Edited by G. L. Hawk. New York: Marcel Dekker.

Tomer, K. B., Jensen, N. J. \& Gross, M. L. (1986). Fast atom bombardment and tandem mass spectrometry for determining structural modification of fatty acids. Anal Chem 58, 2429-2433.

Wang, L., Slayden, R. A., Barry III, C. E. \& Liu, J. (2000). Cell wall structure of a mutant of Mycobacterium smegmatis defective in the biosynthesis of mycolic acids. J Biol Chem 275, 7224-7229.

Watanabe, M., Aoyagi, Y., Ridell, M. \& Minnikin, D. E. (2001). Separation and characterization of individual mycolic acids in representative mycobacteria. Microbiology 147, 1825-1837.

Yuan, Y., Lee, R. E., Besra, G. S., Belisle, J. T. \& Barry III, C. E. (1995). Identification of a gene involved in the biosynthesis of cyclopropanated mycolic acids in Mycobacterium tuberculosis. Proc Natl Acad Sci US A 92, 6630-6634.

Yuan, Y., Zhu, Y. Q., Crane, D. D. \& Barry III, C. E. (1998). The effect of oxygenated mycolic acid composition on cell wall function and macrophage growth in Mycobacterium tuberculosis. Mol Microbiol 29, 1449-1458.

Received 24 September 2001; revised 17 December 2001; accepted 18 December 2001. 